UNIVERSIDADE DE SÃO PAULO

HOSPITAL DE REABILITAÇÃO DE ANOMALIAS CRANIOFACIAIS

\title{
ESTUDO DA POSTURA CORPORAL EM \\ PORTADORES DE DISFONIA
}

\section{ELOISA APARECIDA NELLI}

Tese apresentada ao Hospital de Reabilitação de Anomalias Craniofaciais da Universidade São Paulo, para obtenção do título de DOUTOR em Ciências da Reabilitação.

Área de Concentração: Distúrbios da Comunicação Humana. 
UNIVERSIDADE DE SÃO PAULO

HOSPITAL DE REABILITAÇÃO DE ANOMALIAS CRANIOFACIAIS

\section{ESTUDO DA POSTURA CORPORAL EM \\ PORTADORES DE DISFONIA}

\section{ELOISA APARECIDA NELLI}

Orientador: Prof. Dr. Arnaldo Guilherme

Tese apresentada ao Hospital de Reabilitação de Anomalias Craniofaciais da Universidade São Paulo, para obtenção do título de DOUTOR em Ciências da Reabilitação.

Área de Concentração: Distúrbios da Comunicação Humana. 


\section{UNIVERSIDADE DE SÃO PAULO \\ HOSPITAL DE REABILITAÇÃO DE ANOMALIAS CRANIOFACIAIS}

R. Silvio Marchione, 3-20

Caixa Postal: 1501

17043-900 - Bauru - SP - Brasil

Telefone: (14) 3235-8000

Profa. Dra. Sueli Vilela - Reitora da USP

Prof. Dr. José Alberto de Souza Freitas - Superintendente do HRAC-USP

Autorizo, exclusivamente, para fins acadêmicos e científicos, a reprodução total ou parcial desta dissertação.

Eloisa Aparecida Nelli

Bauru, 18 de agosto de 2006.

Nelli, Eloisa Aparecida

N329e Estudo da postura corporal em portadores de

disfonia. / Eloisa Aparecida Nelli. Bauru, 2006.

54 p.: il.; $30 \mathrm{~cm}$.

Tese (Doutorado em Ciências da Reabilitação - Distúrbios da Comunicação Humana) - Hospital de Reabilitação de Anomalias Craniofaciais, Universidade de São Paulo

Orientador: Prof. Dr. Arnaldo Guilherme

Descritores: 1.Fisioterapia. 2. Postura. 3.Disfonia 
FOLHA DE APROVAÇÃO

Tese apresentada e defendida por

\section{ELOISA APARECIDA NELLI}

e aprovada pela Comissão Julgadora em 1

Prof.(a) Dr.(a):

Instituição:

Prof.(a) Dr.(a):

Instituição:

Prof.(a) Dr.(a):

Instituição:

Prof.(a) Dr.(a):

Instituição:

Prof.(a) Dr.(a):

Instituição:

Profa. Dra. Inge Elly Kiemle Trindade

Presidente da Comissão de Pós-Graduação do HRAC-USP

Data de depósito da tese junto à CPG: 


\section{ELOISA APARECIDA NELLI}

- 24 de maio de 1958: nascimento em Lençóis Paulista/SP.

- 1975 a 1978: Graduação em Fisioterapia na Pontifícia Universidade Católica de Campinas (PUCC), Campinas-SP.

- 1979: Curso de Especialização em Tratamento Neuroevolutivo Método Bobath em São Paulo-SP.

- 1979: Fisioterapeuta responsável pelo Setor de Fisioterapia do HRAC-USP, Bauru-SP.

- 1991 a 1992: Curso de Especialização em Londres-UK.

- 1995: Curso de Especialização em Reeducação Posturale Globale em São Paulo-SP.

- 1996: Curso de Especialização Apliquee Aux Lesions Articulaires em Lion-FR.

- 1993 a 1996: Curso de Pós-Graduação em Ciências da Saúde na Escola Paulista de Medicina (UNIFESP), São Paulo-SP

- 1997: Curso de Especialização Apliquee Aux Lesions Articulaires - Escoliose em São Paulo-SP.

- 1998: Curso de Especialização em Articulação Temporomandibular na Flórida-USA.

- 2004 a 2006: Curso de Pós-Graduação em Ciências da Reabilitação; área de concentração: Distúrbios da Comunicação Humana no HRAC-USP, Bauru-SP. 
Dedico este trabalho aos meus queridos mestres da vida:

Mamãe e Papai... 
Enfrentar o vazio da morte e a dor da separação é e sempre será uma 6atalha muito penosa.

A toda hora, vem a lembrança, as nossas histórias de vida e os 6rilhantes ensinamentos...

... desde o primeiro choro ao sorriso para a vida...

...desde as primeiras artes às tão doídas palmadas para aprendermos o respeito...

... do dar as mãos para os primeiros passos, os passos da dignidade...

... enfrentar as dificuldades e reconhecer os erros para nos tornarmos fortes...

...reconhecer a importância das pessoas que passam por nós... ... que a tristeza nos torna humanos...

...que os nossos sonhos podem se tornar realidade se tivermos força e vontade de realizá-los.

Realmente, nos ensinaram a arte da vida, só não nos ensinaram a curar as saudades. 


\section{Querido Manu}

O valor das coisas não está no tempo em que elas duram, mas na intensidade com que acontecem...

Por isso existem momentos inesquecíveis,

Coisas inexplicáveis e,

Pessoas incomparáveis.

Fernando Pessoa 


\section{AGRADEÇO}

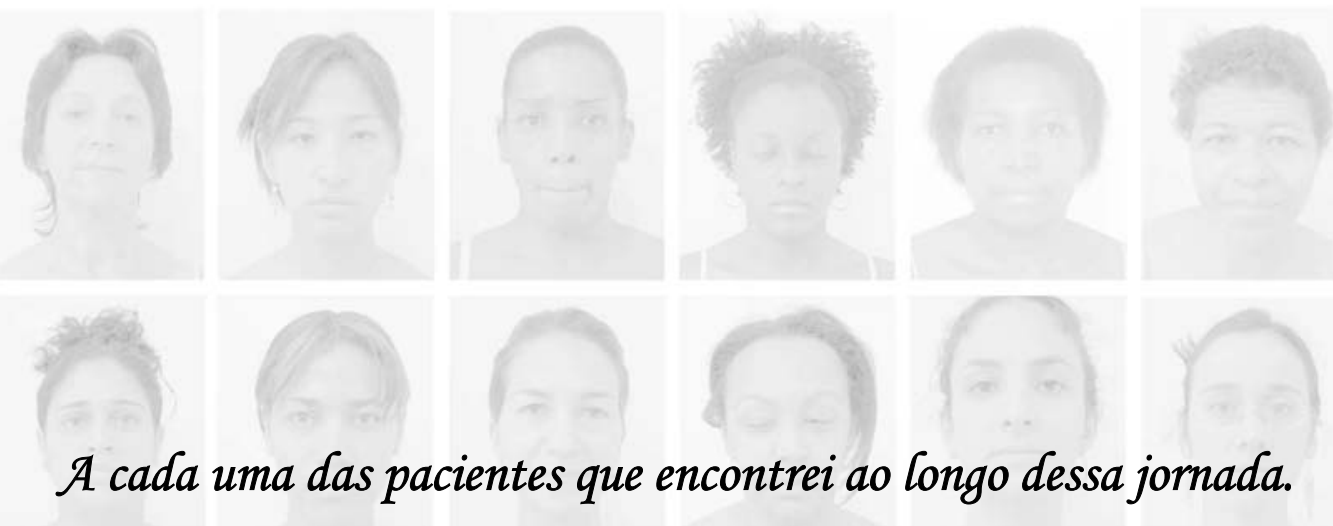

As quais se doaram e depositaram confiança que me motivou a continuar estudando para ajudá-las a se reabilitarem.

Deixo aqui o meu muito obrigada e minha enorme gratidão! 
Agradeço, ainda, às

Inúmeras pessoas que contribuíram de forma decisiva para minha educação, formação e desenvolvimento na carreira universitária; bem como na elaboração deste trabalho.

Apenas mencionar seus nomes não demonstraria o quanto lhes sou grata. Em particular ofereço a cada uma sem as quais não existiria este trabalho, minha gratidão e meu muito obrigada! 


\section{SUMÁRIO}

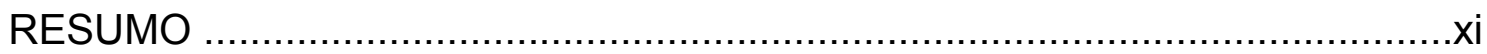

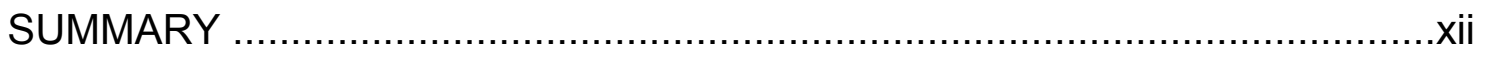

1 - INTRODUÇÃO E REVISÃO DA LITERATURA …………………....pág. 1

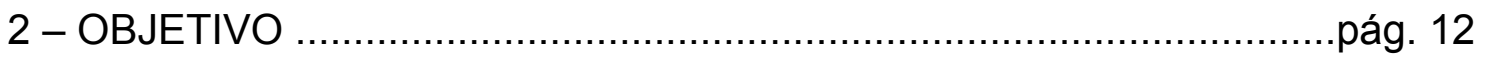

3 - MATERIAL E MÉTODO

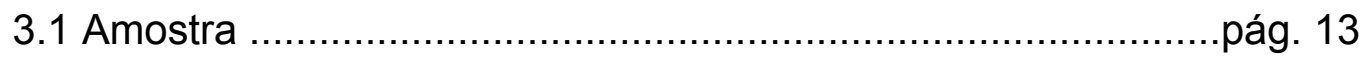

3.2 Metodologia ……................................................................. 14

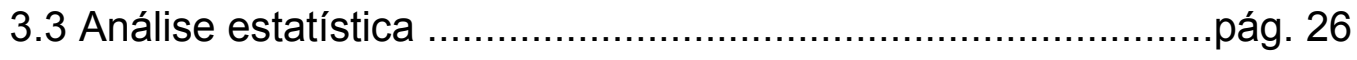

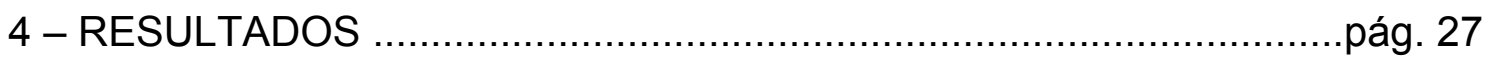

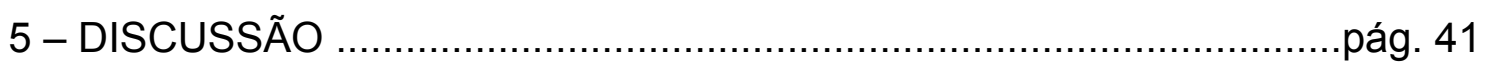

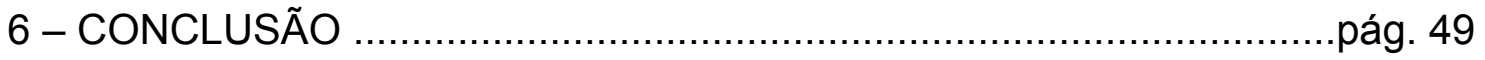

7 - REFERÊNCIAS BIBLIOGRÁFICAS ..............................................pág. 50

ANEXOS 


\section{RESUMO}

NELLI, E A. Estudo sobre a postura corporal de indivíduos portadores de disfonia [Tese] Bauru: Hospital de Reabilitação de Anomalias Craniofacias, Universidade de São Paulo; 2006.

Objetivos: analisar a postura corporal em pacientes disfônicos e correlacioná-los com indivíduos sem alteração de voz, a fim de estabelecer novos recursos terapêutico para reabilitar o portador de disfonia.

Método: estudo prospectivo. Foram avaliados 43 indivíduos (23 disfônicos e 20 sem alteração de voz) do sexo feminino,com idade entre 18 e 40 anos ,sem alterações neurológicas ,respiratórias e reumáticas. Todos os pacientes foram encaminhado pelo serviço de Otorrinolaringologia da Escola Paulista de Medicina ( UNIFESP- EPM),após anamnese, exame do otorrinolaringologista e laringoscopia ,tendo como diagnostico de disfonia funcional ou organofuncional. Nessa população foi avaliado: 1- Postura corporal in loco, 2 - Documentação fotográfica, 3 - Exame Eletromiografia, 4 Questionário das algias.

Resultados: não houve diferença estatisticamente significante em relação à queixa,porem foi encontrado um numero maior de tensão muscular e dor na região cervical, onde se encontra situado a laringe, nos portadores de disfonia. $\mathrm{Na}$ avaliação postural, os indivíduos disfônicos apresentarão assimetria de ombros, alteração no posicionamento da escapula, retificação com anteriorização da região cervical em relação ao grupo controle. Nos resultados da Eletromiografia houve aumento das atividades nos músculos supra-hióideo em emissão prolongada, controlada e deglutição. Nos músculos infra-hióideo houve alteração no traçado eletromiógrafico na emissão prolongada .

Conclusão: pode- se concluir que o estudo mostra a existência da correlação positiva entre indivíduos portadores de disfonia e alteração na postura, baseado nas diferenças dos achados clínicos e medidas eletromiográficas.

Descritores: fisioterapia, postura, disfonia 


\section{SUMMARY}

NELLI, E A. Investigation of the body posture of individuals with dysphonia [Thesis] Bauru: Hospital de Reabilitação de Anomalias Craniofacias, Universidade de São Paulo; 2006.

Objectives: This study analyzed the body posture of dysphonic patients and correlated them with individuals without voice alterations, in order to establish new therapeutic resources to rehabilitate the patients with dysphonia.

Method: prospective study. A total of 43 individuals were analyzed ( 23 with dysphonia and 20 without voice alterations), of female gender, aged 18 to 40 years, without neurological, respiratory and rheumatic alterations. All patients were referred by the ENT Sector of Paulista Medical School (UNIFESP- EPM) after anamnesis, ENT examination and laryngoscopy, with diagnosis of functional or organofunctional dysphonia. The following parameters were investigated in this population: 1- Body posture in loco, 2- Photographic records, 3- Electromyographic examination, 4Questionnaire on pain.

Results: The results indicated no statistically significant difference with regard to the complaint, yet a larger number of individuals with dysphonia reported muscle tension and pain at the cervical region, where the larynx is located. Posture evaluation revealed that dysphonic individuals presented shoulder asymmetry, alterations in scapular positioning and rectification with forward displacement of the cervical region compared to the control group. The results of electromyographic analysis demonstrated increased activity of the suprahyoid muscle in prolonged emission, controlled emission and swallowing. The infrahyoid muscles exhibited altered electromyographic tracing during prolonged emission.

Conclusion: It was concluded that there is correlation between individuals with dysphonia and posture alterations, based on the differences in clinical findings and electromyographic measurements.

Key words: physical therapy, posture, dysphonia 


\section{INTRODUÇÃO E REVISÃO DA LITERATURA}

A comunicação oral depende da habilidade do falante, contato de olhos, movimento do corpo, qualidade vocal adequada e uma boa postura (Collins 2004).

O termo "boa postura" sugere posição em pé que satisfaça especificações da estética e mecânica (Bricot 1999).

Vários autores definiram postura ao longo dos anos. Basmajian, em 1978, definiu como sendo "posição vertical bem equilibrada de um sujeito em uma posição normal", e acrescentou: Postura envolve os mecanismos de manutenção do equilíbrio quando forças estão atuando no corpo em várias direções. A manutenção do equilíbrio é fundamental, e a desorganização de um segmento do corpo implicará em uma nova organização de todos os outros. Assim, por exemplo, se a cabeça é colocada à frente, conseqüentemente as costas assumem posição para trás e o ventre para frente em um deslocamento de massa, de força e direção contrária a toda força desequilibrante.

Kendal e Mc Creary (1987 ) definiram postura padrão como sendo: uma quantidade mínima de esforço e sobrecarga, que conduz a uma eficiência máxima no uso do corpo.

Segundo Shouchard (1987), na postura ereta, os pés devem estar à frente dos tornozelos, conseqüentemente a linha da gravidade que cai no meio deles é encontrada à frente desta articulação, provocando um desequilíbrio anterior. Para corrigi-lo, obedecendo a lei do mínimo esforço, o joelho situa-se ligeiramente atrás da linha da gravidade, o ventre à frente, as costas atrás e a cabeça à frente. 
Já Schneider et al (1997) descreveram a postura ideal, normal e ereta na qual a linha de gravidade é desenhada pelos seguintes pontos, anteriores à coluna vertebral: a) processo mastóideo, b)ponto imediatamente anterior à articulação do ombro, c) ponto imediatamente posterior à articulação do quadril, d) ponto imediatamente anterior ao centro da articulação do joelho, e e) ponto imediatamente anterior à articulação do tornozelo. Representa o equilíbrio da atividade muscular que mantém ou realinha o corpo para sua posição estável.

As conseqüências de uma má postura são descritas por Calliet (1997), que faz referência à cabeça anteriorizada: seu peso relativo torna-se maior e o pescoço assume posição com lordose mais acentuada; os forames intervertebrais se estreitam, colocando pressão sobre as raízes dos nervos cervicais; os ombros rodam para frente e para baixo causando carga excessiva sobre a musculatura escapular.

Souchard (1987) afirmou: cada vez que um músculo se encurta, ele mantém suas extremidades próximas e conseqüentemente os ossos que estão inseridos a ele também, desorganizando outros com origem ou inserção nestes ossos, e assim sucessivamente.

Com a evolução da espécie animal, a postura vem sofrendo modificações, passando da posição de quatro apoios para adotar a bípede. Com isso, vários músculos sofreram alterações para manterem sua função.

O estado emocional do indivíduo pode, também, alterar o padrão postural.

A voz é o mais importante meio de comunicação para o ser humano, tendo características pessoais particulares, e traduz a personalidade e estado emocional do indivíduo, devendo ser agradável para o ouvinte. Assim, a 
laringe, órgão responsável pela função, deverá estar o mais próximo possível das condições ideais de funcionamento (De Biase 1997).

Quando isso não ocorre, pode haver a disfonia, que é, na realidade, um sintoma presente em vários e diferentes distúrbios, ora apresentado como secundário, ora como principal. Muitas vezes é o sintoma mais importante de uma doença, sendo por isso encarado como a própria doença como ocorre nos casos de disfonia funcional, outras vezes, de um sintoma discreto inserido num quadro maior, como no caso da doença de Parkinson (Behlau e Pontes, 1995). Gould (1971) descreveu três fatores básicos que são particularmente pertinentes na relação produção vocal e mecanismo postural: 1) pressão subglótica positiva (que ocorre durante a respiração normal); 2) o fluxo aéreo expiratório do sistema pulmonar (necessário para criar um fenômeno de Bernoulli) e, 3) o efeito pulmonar inspiratório requer não somente o suporte da musculatura torácica e abdominal, mas também a abdução coordenada das pregas vocais. Além disso, o autor notou que músculos abdominais e intercostais são essenciais tanto para respiração como para produção da voz (conexão da voz, postura e respiração). Em relação ao mecanismo respiratório, foi observado que a musculatura de suporte para ambos (postura e respiração), tanto arco costal, como músculo abdominal, estão inter-relacionados, e foi demonstrado que mesmo durante o movimento normal da respiração (troca do oxigênio pelo gás carbônico) existe uma parcial dependência entre a postura corporal e da abertura da caixa de ressonância. Segundo o autor, o estudo evidencia que esse mecanismo do corpo equilibra membros superiores e músculos do pescoço e indiretamente influencia na respiração e fala, que ajudam o suporte da caixa torácica. Observou ainda, que o mecanismo do SNC 
é a regra em integração postural, laríngea e controle diafragmático, com especial ênfase em feixes de fibras neuromusculares que auxiliam na produção da voz.

Em indivíduos portadores de disfonia pode haver uma correlação entre o aumento da atividade dos músculos responsáveis pela postura da cabeça e pescoço, ou seja, o som de uma voz forçada pode corresponder ao aumento da tensão perilaringeal durante fonação causada por ação muscular imprópria. Nesse tipo levando a uma tensão nos músculos do pescoço, resultando em disfunções de cordas vocais, resultando em disfonia (Grini 1998). Em nossa observação clinica, os pacientes que freqüentemente apresentam anteroposição da cabeça e pescoço, acentuam a lordose fisiológica, provavelmente devido a tensão muscular do esternocleidomastóideo-trapéziopeitoral. A tensão pode ser minimizada com uma boa postura, como relatado por Jones (1972), que observou alterações do equilíbrio da cabeça durante o canto. Neste estudo foi possível concluir sobre o maior controle da respiração quando a postura estava corrigida, além do melhor aproveitamento das cavidades de ressonância, inibindo o aumento na tensão dos músculos do pescoço durante a fala ou canto, podendo exercitar um controle indiretamente o qual facilita a produção da voz. Corroborando, Schneider et al. (1997) descreveram o canto, como uma atividade que não somente envolve o treinamento, uso e adaptação do mecanismo da voz, mas que, também, necessita do alinhamento postural apropriado. As alterações posturais cervicais podem ser melhor compreendidas em suas relações com as funções desempenhadas pelo ser humano quando analisada a anatomia da região cervical anterior e posterior. Anteriormente, localiza-se a laringe, cujo esqueleto 
é formado por cartilagens, músculos, membranas e mucosa. Divide-se em três espaços: supra-glote, glote e infra-glote. Segundo a descrição de Behlau (2001), a musculatura laríngea é dividida em 2 grupamentos funcionais, os músculos intrínsecos e os músculos extrínsecos. São denominados intrínsecos os que têm origem e inserção na laringe, ao passo que os extrínsecos apresentam apenas uma das inserções na laringe e outra fora dela. Os intrínsecos são tireoaritenóideo, cricoaritenóideo posterior, cricoaritenóideo lateral, aritenóideo, cricotireóideo, ariepiglótico e tireoepiglótico. A musculatura extrínseca é formada por músculos inseridos nas cartilagens laríngeas, porém provenientes de estruturas não-laríngeas. A hipertonicidade desses pode ser um fator muito importante nos casos de disfonia por tensão muscular, elevando a laringe no pescoço, aumentando a massa muscular e tornando a palpação dolorosa. Os músculos extrínsecos dividem-se em dois grupos: músculos suprahióideos e infrahióideos, de acordo com sua inserção no osso hióideo e sua função principal. São inervados pelo V, VI e XII pares cranianos.

Nas regiões lateral e posterior do pescoço, encontramos o músculo esternocleidomastóideo, trapézio, semi-espinhal da cabeça, esplênio da cabeça, esplênio do pescoço e escalenos. Todos são inervados pelo XI par. O esternocleidomastóideo é um importante músculo, com a função de flexão do pescoço, trabalhando com músculos acessórios, principalmente os infrahióideos (Lacôte et al 1987).

Segundo Grini, Ouaknine, Giovanni (1998) a voz forçada corresponde ao aumento da tensão perilaringeal, durante a fonação causada pela ação muscular inapropriada, usualmente acompanhada pela característica postural (face projetada para frente, tensão nos músculos do pescoço, etc.). Tal postura 
pode causar disfunção das pregas vocais, levando à disfonia. Visaram validar a objetividade do sistema, usando medidas não evasivas da característica postural na voz forçada, para adequar a conduta para os pacientes. No estudo, que foi prospectivo, comparando grupo controle, formado por indivíduos que não apresentavam problemas vocais, com o grupo que apresentavam disfunção laringeal, implantaram um número de medidas simultâneas da postura e atividade segmental durante a fonação, usando em paralelo um acelerômetro, método de cine-análise, e plataforma postural. Realizaram gravações durante a fonação, mas apenas efetuaram análises durante a fase de repouso. Foi verificado, então, que a velocidade do deslocamento do centro de gravidade foi o fator mais discriminante, concluindo favoravelmente, que a confiabilidade das medidas utilizadas permitem a inclusão dessas na avaliação geral do indivíduo com relação às mudanças posturais e segmentais na voz forçada.

Ainda com relação à tensão muscular, Behrman (2005) e Ogawa et al (2005) verificaram que a disfonia por tensão está associada a uma contração excessiva da musculatura laríngea e postura anormal da laringe.

Kooijiman et al (2005) investigaram a relação entre a hipertonicidade muscular extrínseca da laringe e o desvio da postura corporal em professores com queixas vocais persistentes e história de alteração da voz. A amostra foi de 25 professoras, que foram avaliadas por um fonoaudiólogo, que testou a tensão da musculatura extrínseca da laringe e um fisioterapeuta, que avaliou a postura corporal. Foi criado um índice tensão/postura e correlacionado a índices de avaliação vocal, o Voice Handicap Index - VHI (Índice de Alteração Vocal) e o Dysphonia Severity Index - DSI (Índice de Gravidade da Disfonia). O 
escore do índice tensão/postura teve uma correlação significante com ambos os índices de avaliação vocal. Segundo os autores, a combinação de hipertonicidade do esternocleidomastóideo, do músculo geniohióideo e a posição de peso posterior é o preditor mais importante para uma alta deficiência vocal. A posição alta do osso hióideo, a hipertonicidade do músculo cricotireóideo e a anteroposição são os índices mais importantes para um baixo escore do DSI. Os resultados deste estudo mostram que, quanto maior o escore do índice, maior o escore de alteração vocal e pior a qualidade vocal. Além disso, os autores afirmaram que os resultados indicam o quanto é importante a avaliação da tensão muscular e da postura corporal no diagnóstico dos distúrbios da voz.

Grini-Grandval, Ouaknine e Giovanni (2000) usando a estabilometria, realizaram estudo experimental para demonstrar o parâmetro quantitativo da postura em relação a voz forçada. A análise de intervalos utilizados mostrou a perfeita correlação entre aumento na variância da velocidade do deslocamento do centro da gravidade e o aumento no sinal elétrico dos músculos da postura. Evidenciaram essa ação durante o esforço da voz, bem como sua expressão clínica, e a necessária intervenção de outros estudos como gravação cinematográfica da respiração.

Segundo Gregg (1997), o conhecimento da anatomia e fisiologia do mecanismo e plexo vocal é essencial para a voz do professor ser eficaz. Para o mesmo autor, os possíveis fatores que contribuem para o hábito vocal inadequado na maturidade do cantor e do ator são: postura pobre, inadequada função respiratória, carência de hidratação adequada, hiper-função fonatória, hábito de falar em alta freqüência, mal aproveitamento das caixas de 
ressonância e tensão da língua afetando a articulação. Recomenda técnicas para reabilitação vocal.

Xue, Mueller (1997) investigaram as características perceptuais e acústicas da voz, relacionadas com a atividade física e sedentária de locutores idosos. Na ocasião foi utilizada a gravação da vogal /a/ sustentada, em 31 locutores do sexo masculino e feminino. Vinte adultos ouvintes julgaram a idade cronológica dos locutores velhos em suas performances orais. Os seguintes parâmetros acústicos foram analisados: freqüência fundamental, desvio padrão da freqüência fundamental, (jitter) por cento, shimmer em dB e proporção harmônico-ruído foram medidas das fonações de vogais sustentadas dos falantes idosos. Os resultados indicaram que locutores idosos fisicamente ativos foram classificados como cronologicamente mais jovens,tiveram menos jitter por cento e desvio padrão da freqüência fundamental do que os correspondentes sedentários, mostrando a importância da atividade física e a relação entre a musculatura cervical e a voz.

Outro estudo com idosos, realizado por Salvinelli et al (2003), concluiu que há necessidade para se estabelecer um diagnóstico de disfonia sem causa primária da laringe, de um estudo radiológico da região cervico-torácica, para verificar osteofitose. Após a correção dessa alteração, a dissectomia cervical (cirurgia realizada para reposicionamento e correção de vértebras e discos), é comum ocorrer disfunção pós-cirúrgica da voz e deglutição, em parte por edema de tecido mole no pescoço (Frempong-Boadu et al 2002, Hartman et al 2005 e Winslow et al 2001). 
Em 1999, Pinho et al concluíram que, "dependendo da deficiência vocal relatada, o paciente tenderá a compensar usando diferentes evoluções, tal como incrementar o trato vocal e contrair os músculos do pescoço".

Uma das formas de estudar a atividade muscular com a tensão vocal é a eletromiografia de superfície. Redenbaugh e Reich (1989) avaliaram 14 sujeitos, 7 disfônicos e 7 com disfonia com fadiga vocal e constrição muscular no pescoço anterior, sendo 5 do segundo grupo com sinais visíveis de tensão excessiva nessa musculatura. Foram avaliados por três fonoaudiólogos por meio de palpação laríngea e eletromiografia. À palpação, a tonicidade da área laríngea foi classificada usando uma escala de 5 pontos, onde 1 era tonicidade normal e 5 hipertonicidade muito grave. Na eletromiografia foram avaliados os músculos do pescoço anterior, com eletrodo bipolar, usando a vogal /a/ prolongada, contagem em voz alta e a voz espontânea contínua. Os falantes com hiperfunção vocal apresentaram valores da avaliação da eletromiografia (EMG) no repouso maiores do que os falantes normais. Boltezar et al (1998) estudaram a tensão muscular na disfonia, pelo emprego de EMG na superfície da região do peitoral e região anterior do pescoço, antes e durante a fonação. Não ficou claro, se os músculos desta região apresentaram compensação por excessiva tensão, ou se eles foram responsáveis por alguma desordem da voz. Outros estudos com EMG foram realizados, como de Pettersen e Westgaard (2005), que fizeram a avaliação eletromiográfica superficial dos músculos trapézio, esternocleidomastóideo, escaleno em 5 cantores de ópera, onde relataram que houve um aumento da atividade de todos os músculos do pescoço quando emitiam sons agudos. Outros estudos foram realizados envolvendo a EMG de superfície. 
Forsberg et al (1985) usaram a eletromiografia nos músculos mastigatórios e do pescoço em relação à extensão e flexão da cabeça, encontrando aumento da atividade nos músculos supra e infra-hióideos durante a extensão e flexão de $20^{\circ}$, alterando o equilíbrio da cabeça na coluna vertebral.

Stemple et al (1980) avaliaram a tensão da laringe e técnicas terapêuticas para distúrbios vocais por hiperfunção como o treinamento por biofeedback eletromiográfico na redução da tensão muscular da referida região em pacientes com nódulos vocais. Com relação à essa avaliação, foi observado que em média, os sujeitos com nódulos vocais tiveram níveis mais altos de tensão geral da musculatura da área laríngea durante a fala e durante o silêncio, do que os normais. Com relação ao treinamento, foi provado o sucesso ao ajudar pacientes com distúrbio vocal por hiperfunção a eliminar os comportamentos inadequados, principalmente posicionar corretamente a laringe elevada. Além disso, essa avaliação foi utilizada em canto e com outros profissionais que usam a voz como instrumento de trabalho (Buder e Wolf 2003), ou com relação ao tratamento de Botox (Kimaid et al 2004 e Sulica e Blitzer 2004).

Durante revisão da literatura específica, foi possível observar que na maioria das publicações encontradas são considerados os aspectos voz e postura de maneira isolada. No entanto, poucos autores relatam a possível correlação entre esses dois parâmetros. Além disso, depois de extensa pesquisa bibliográfica, foi possível observar que o tema é escasso, e que existem poucos artigos que mostraram a correlação sistemática entre postura e 
voz, através de métodos objetivos de avaliação, tanto no que diz respeito à postura como em relação à voz.

A fonação não é apenas o resultado da atividade dentro da laringe. A atividade muscular do corpo inteiro é também responsável pela função apropriada da mesma (Kooijiman et al 2005). Assim, como ressalta Schneider et al (1997), a postura é um importante componente da performance vocal, podendo ser um dos fatores que contribuem para a disfonia por mau uso vocal (Morrison 1997), sendo fundamental o trabalho do fisioterapeuta em casos de alterações vocais.

Sendo assim, investigações mais extensivas são necessárias para elucidação dos mecanismos posturais, como elemento base tanto para respiração como para a emissão da voz, procurando maiores subsídios para justificar a atuação do fisioterapeuta no tratamento coadjuvante do indivíduo disfônico. 


\section{OBJETIVO}

O objetivo deste estudo é de analisar a postura corporal em pacientes disfônicos através de parâmetros antropométricos e de eletromiografia e comparar seus resultados com o de indivíduos sem alteração de voz. 


\section{MATERIAL E MÉTODO}

\subsection{Amostra}

Foram avaliados 23 indivíduos disfônicos, do sexo feminino, com idade entre 18 e 39 anos (média de 28 anos), sem alteração neurológica, respiratória e reumática. Esta faixa etária de 18 a 40 anos foi escolhida por apresentar indivíduos que já tinham completado o crescimento ósseo (18 anos) e também excluir possíveis alterações que ocorrem após 40 anos, como processos degenerativos, tais como osteoporose e presbifonia.

Os mesmos critérios foram utilizados para constituir um grupo controle, composto por 20 indivíduos do sexo feminino, com idade que variou entre 18 e 39 anos (média de 29 anos), sem disfonia.

Os indivíduos disfônicos foram encaminhados pelo Serviço de Otorrinolaringoloia da Escola Paulista de Medicina (UNIFESP-EPM) após anamnese, exame do otorrinolaringologista e laringoscopia. Para a inclusão neste trabalho, todos tiveram o diagnóstico de disfonia funcional ou organofuncional.

Os critérios de exclusão (anexo 4) foram doença reumática, má formação óssea e desvios posturais severos, paralisia cerebral, síndromes genéticas e, cintura escapular e membros superiores. Os mesmos critérios de exclusão se aplicaram para indivíduos sem disfonia (grupo controle). 


\subsection{Metodologia}

Após avaliação e aprovação da Comissão de Pesquisa e do Comitê de Ética em Pesquisa em Seres Humanos do HRAC-USP (anexo 1), foram elaborados a Carta de Informação ao Sujeito da Pesquisa (anexo 2) o Termo de Consentimento Livre e Esclarecido (anexo 3). Os indivíduos foram informados quanto à pesquisa com os dados da Carta de Informação ao Sujeito da Pesquisa (anexo 2) e assinaram o Termo de Consentimento Livre e Esclarecido (anexo 3). As avaliações foram realizadas no Instituto da Laringe (INLAR-SP).

Foram examinadas sistematicamente as alterações posturais dos indivíduos, por avaliação postural e documentação fotográfica e eletromiografia.

Todos os participantes deste estudo foram submetidos a uma avaliação completa (anexo 5), constando de:

1) Questionário

2) Avaliação postural in loco

3) Avaliação postural fotográfica

4) Avaliação eletromiográfica

O questionário incluiu anamnese quantitativa da incidência da algia cervical, dorsal e lombar, sendo esses dados comparados entre os grupos com e sem disfonia.

A avaliação postural foi realizada nas seguintes posições em pé: frente, perfil e costa. Seguindo as observações de Magee (2002), os indivíduos foram avaliados com roupa íntima. 
$\mathrm{Na}$ avaliação da frente, foi considerada normal a postura dos indivíduos que apresentavam simetria facial, da linha dos lóbulos auriculares, de ombros, clavículas, triângulo de Talles, crista ilíaca, joelhos e maléolos. Quanto ao perfil, foi observado o padrão de normalidade, referente às curvaturas fisiológicas da coluna vertebral. Na avaliação posterior (costa) do indivíduo, foi considerada normal a simetria escapular, linha glútea e posição de calcâneo. No presente estudo, não foram realizadas tomadas radiográficas para as medidas de angulação da coluna, pois foi adotada a tabela-resumo de Magee (2002), como base para estabelecer a boa e a má postura, uma vez que o objetivo deste foi analisar a musculatura e não a estrutura óssea.

Durante as avaliações, foi solicitado para o indivíduo se manter em uma postura habitual, onde somente foi corrigido o posicionamento do apoio plantar, deixando os pés alinhados e orientando a distribuição do peso em toda a região plantar.

Os indivíduos foram fotografados com uma máquina digital, de marca Casio- Digital Câmera QV-R51 3x optical zoom 5.0 mega pixels, em pé, em três posições (frente, costas e perfil), em duas visões cada (perto e longe), como observado nas figuras 1 a 6 .

No traçado fotográfico, foi usado o fio de prumo, cujo alinhamento foi realizado nas três vistas anterior, lateral e posterior.

$\mathrm{Na}$ vista anterior, foram utilizados como pontos de referência a linha sagital, compreendendo a ponta do nariz, o mento, o centro do esterno, linha Alba, cicatriz onfálica e sínfise púbica e este alinhamento deverá estar na linha média entre os membros inferiores. 
$\mathrm{Na}$ vista posterior, foram tomados como pontos de referência a linha sagital, compreendendo atlas, axis, todos os processos espinhosos, espinha sacral e este alinhamento deverá estar na linha média entre os membros inferiores encontrada na vista anterior.

$\mathrm{Na}$ vista lateral, e aqui cabe ressaltar que é necessário analisar vista lateral direita e vista lateral esquerda, pois, em indivíduo com desalinhamentos posturais, as respostas são diferentes, o ponto de referência foi a linha coronal, compreendendo lóbulo da orelha, acrômio, trocanter maior do fêmur, côndilo lateral da tíbia, e imediatamente à frente do maléolo externo. Essa metodologia seguiu Fornasari (1994). Todos os indivíduos foram submetidos ao mesmo tipo de avaliação e, em todas as fotos foi traçada uma linha reta, nas posições anteroposterior, perfil e costas, para melhor análise dos segmentos do corpo, sendo dado um enfoque maior na postura cervical devido à localização da laringe.

Foi adotado o padrão postural da estática normal proposto por Magee (2002) (figuras 7 e 8) em relação aos planos:

\section{Estática Normal:}

A) Plano sagital

Eixo vertical do corpo passando pelo vértice apófise espinhosa C2, corpo vertebral lombar, alinhamento escapular e pélvico.

B) Plano Frontal:

Linhas horizontais entre as pupilas, os dois tragus, mamilos, cintura escapular e pélvica, alinhamento dos joelhos e maléolos. 
C) Plano Horizontal:

É visto um bloco sem alterações ao nível das cinturas escapular e pélvicas.

Postura normal = ausência de forças contrárias, = inexistência de dor relações harmoniosas
A. Individuo normal
B. Planos alinhados, aumento das curvaturas
C. Plano escapular posterior
D. Dorso plano, plano escapular anterior
E. Planos alinhados, diminuição das curvaturas

Todos os indivíduos foram avaliados por uma fisioterapeuta, sendo as fotografias analisadas por duas fisioterapeutas, com $100 \%$ de consenso. 


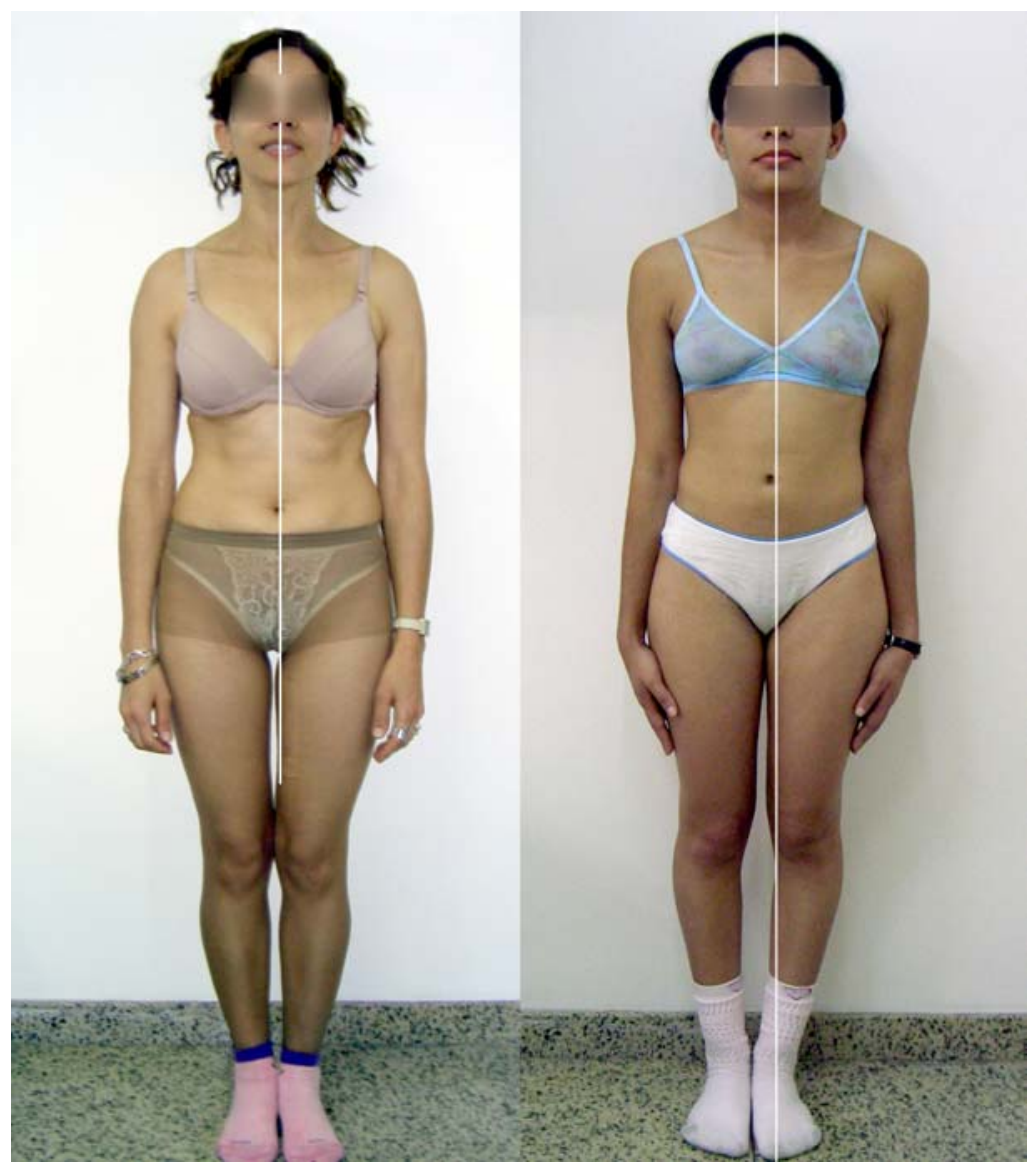

A

B

Figura 1- Vista anterior do corpo

A- normal

B- patológico

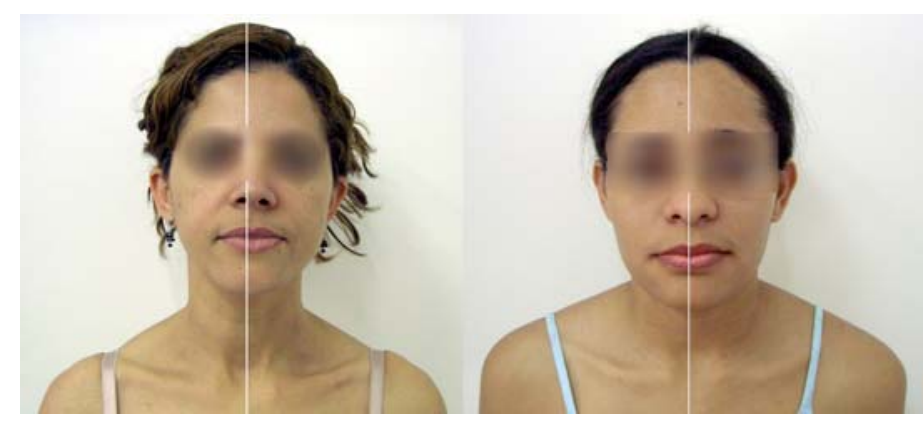

A

B

Figura 2- Vista anterior do ombro e da cabeça A- normal

B- patológico 


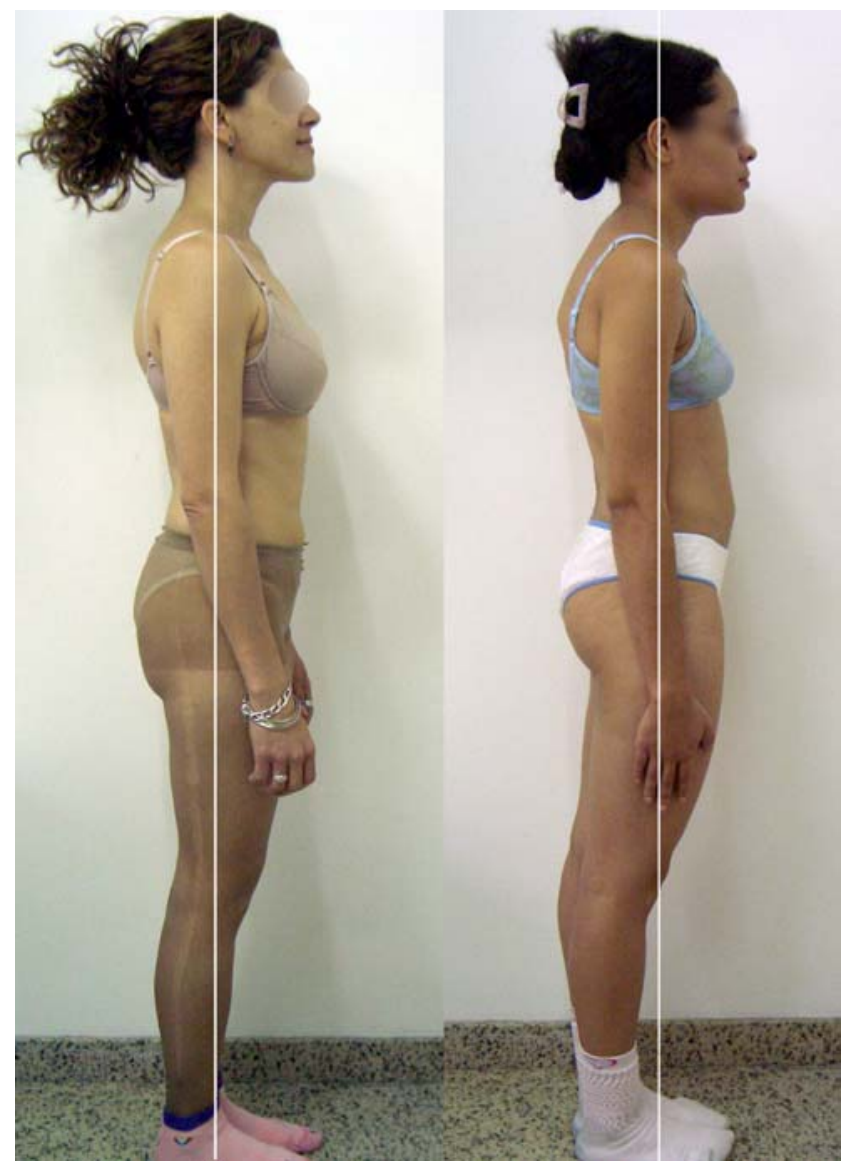

A

B

Figura 3- Vista de perfil do corpo

A- normal

B- patológico

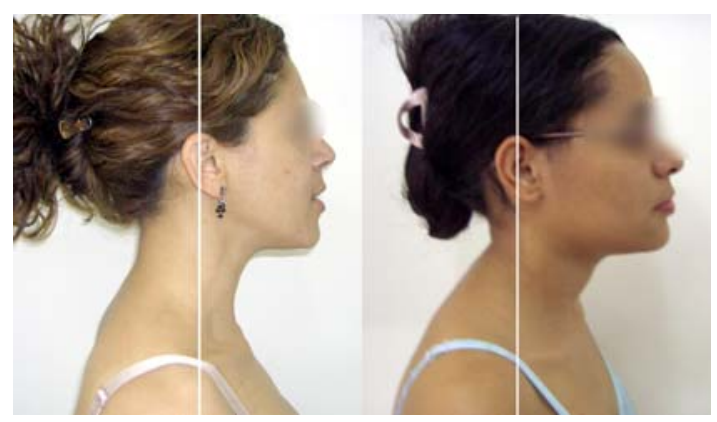

Figura 4- Vista de perfil do ombro e da cabeça

A- normal

B- patológico 


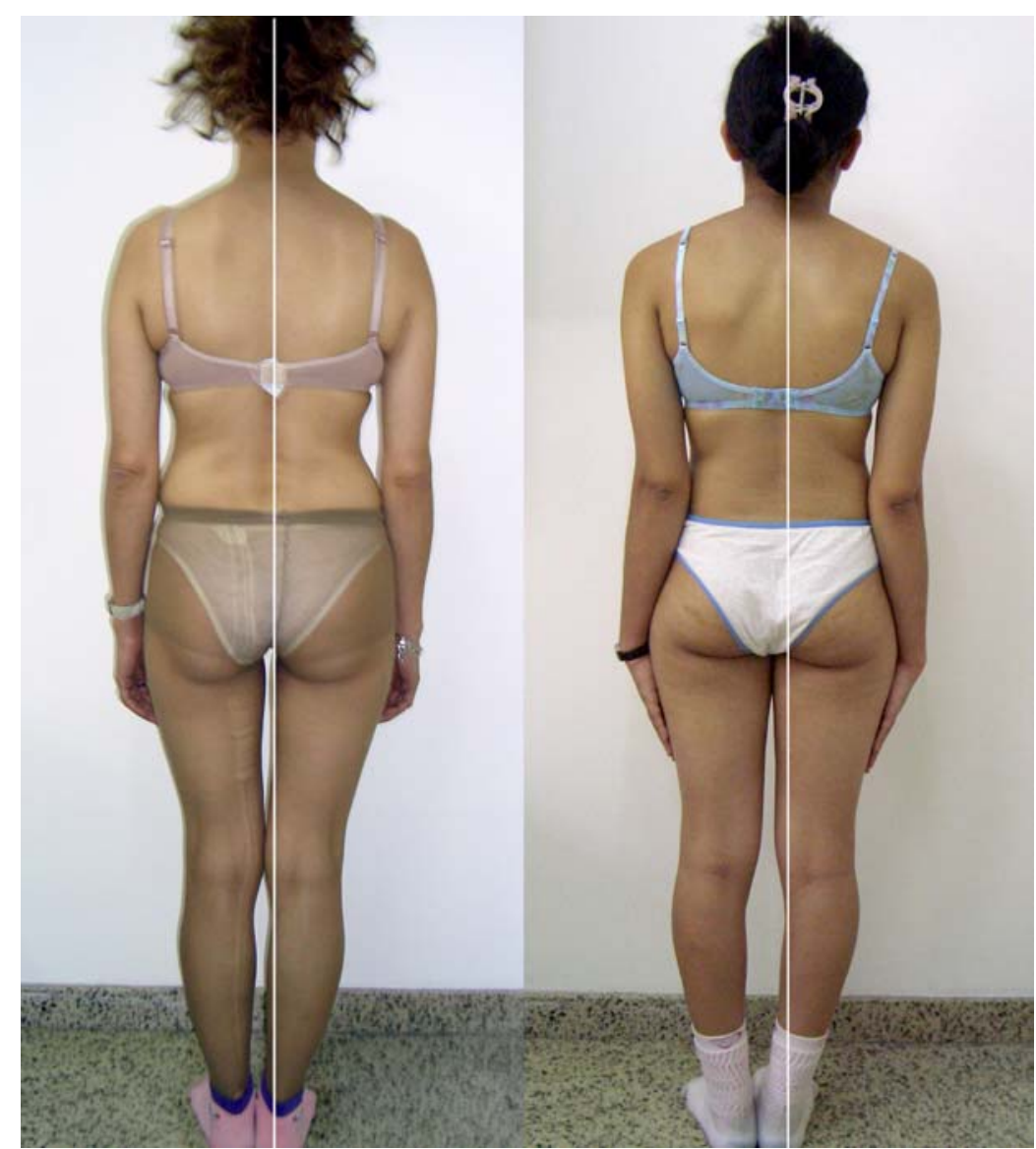

A

B

Figura 5- Vista posterior do corpo

A- normal

B- patológico



Figura 6- Vista posterior do ombro e da cabeça

A- normal

B- patológico 


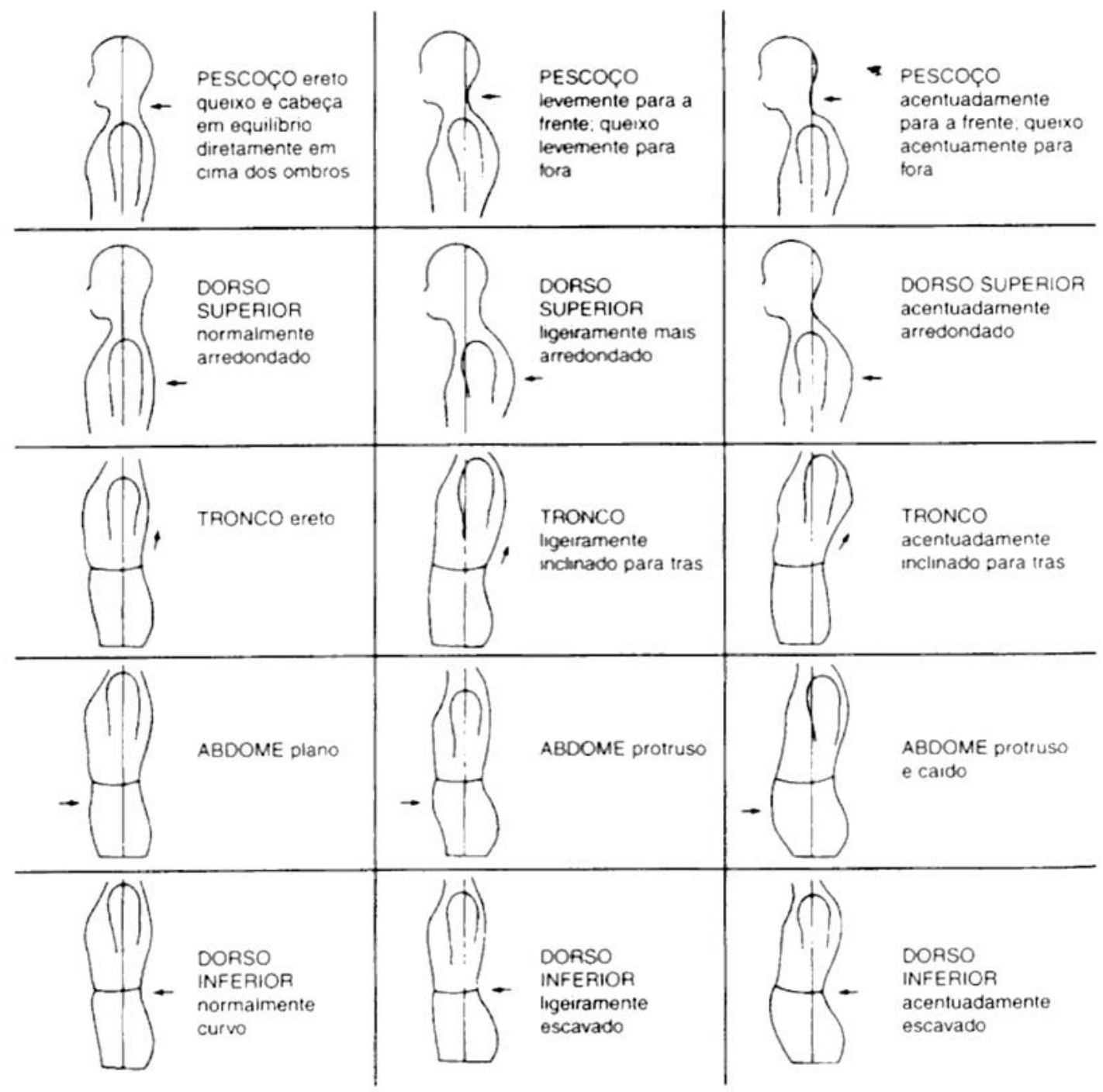

Figura 7- Representação esquemática das variações posturais na posição de perfil

Fonte: Magee D. Avaliação músculo-esquelética. 3a.ed. Barueri: Manole; 2002. 


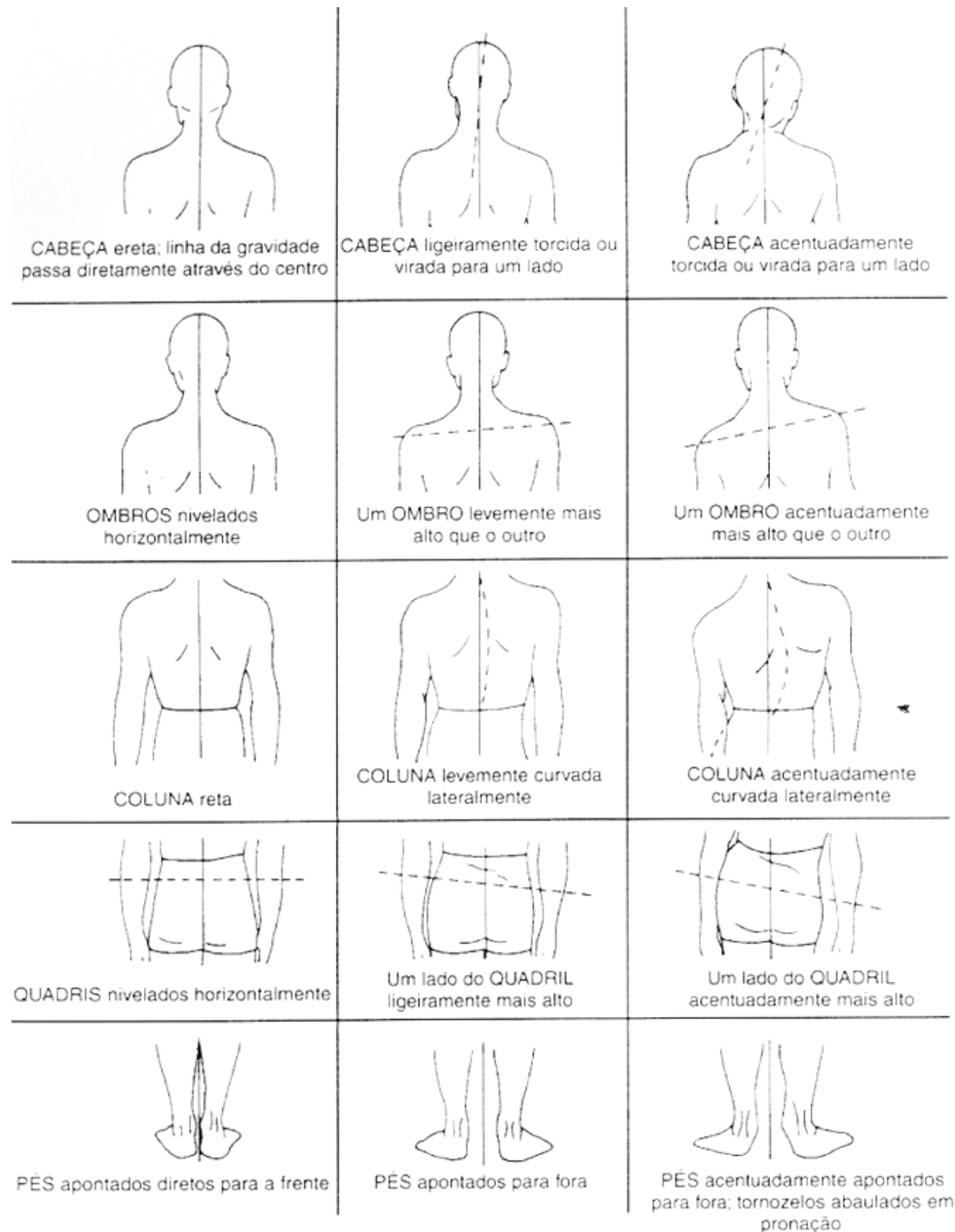

Figura 8 - Representação esquemática das variações posturais na posição posterior

Fonte: Magee D. Avaliação músculo-esquelética. 3a.ed. Barueri: Manole; 2002. 
Também foi realizada a avaliação eletromiográfica (figura 9) de grupos musculares da região cervical, sendo o equipamento utilizado o eletromiógrafo Nicoletti com o programa Compass Meridian II. Para a eletromiografia de superfície, foram utilizados eletrodos monopolares descartáveis, de $11 \mathrm{~mm}$ de diâmetro, pesando 250mg, da marca Noraxon Dual Electrods com adesivos posicionados no terço médio do músculo esternocleidomastóideo (ECM), região suprahióidea, e infrahióidea. Foram avaliados os músculos do lado direito por convenção dos avaliadores Um eletrodo-terra foi posicionado abaixo da proeminência óssea da clavícula, do lado oposto ao examinado. $O$ aparelho permitiu a utilização de dois canais de registro. O primeiro canal foi utilizado para o registro da atividade elétrica gerada pelos músculos. O segundo canal registrou as ondas sonoras captadas por microfone, posicionado a $15 \mathrm{~cm}$ da boca do indivíduo.

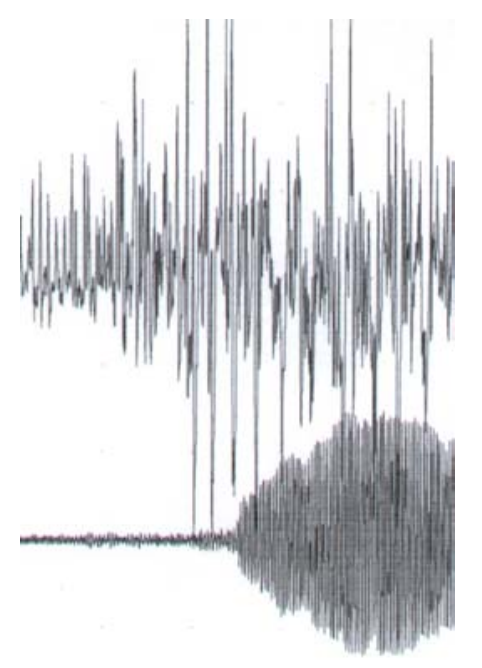

\section{NVDiv, $20 \mathrm{~ms} D \mathrm{Di}$ \\ 100 NVDiv, 20 ms Div}

Figura 9 - llustração de traçado eletromiográfico 
Todos os registros foram feitos na mesma sessão, procurando manter as condições experimentais inalteradas em cada indivíduo e evitar possíveis fontes de erros, tais como variações na localização de eletrodos, temperatura, tensão, entre outras.

Os indivíduos foram examinados na posição sentado confortavelmente, em uma cadeira, com a cabeça naturalmente posicionada e o olhar direcionado a frente (figura 10), conforme nos relatos de Ribeiro et al (2003). Cuidados como a angulação coxo-femural, joelho e tornozelo em $90^{\circ}$ foram tomados. Foi orientado para que mantivessem a respiração normal e a região cervical estática durante os registros da eletromiografia.

Em cada grupo muscular, foram feitos diferentes registros durante 0 exame: - em repouso

- durante emissão da vogal /a/ sustentada

- durante contagem de 1 a 10

- durante a emissão da frase "Um homem e uma mulher viram um pássaro voando". A frase tem predomínio de sons sonoros, com maior participação da laringe (Behlau 2001).

- deglutindo saliva

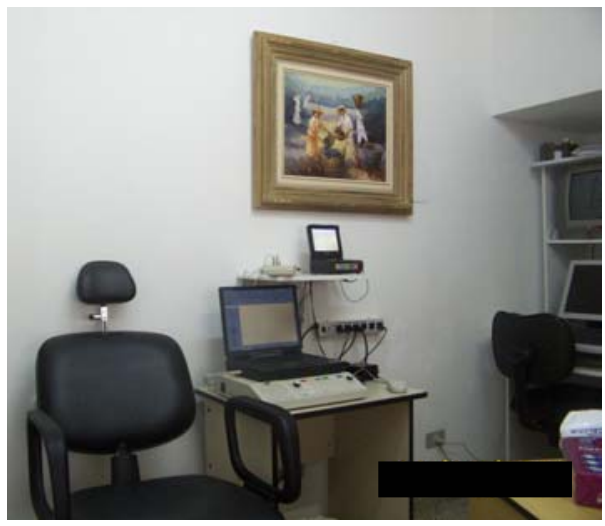

Figura 10- Local de avaliação eletromiográfica 
As medidas analisadas foram:

SHR - músculos suprahióideos no repouso

SHA - músculos suprahióideos durante a emissão da vogal /a/

SHC - músculos suprahióideos durante a contagem

SHF - músculos suprahióideos durante a frase

SHD - músculos suprahióideos durante a deglutição

IHR - músculos infrahióideos no repouso

IHA - músculos infrahióideos durante a emissão da vogal /a/

IHC - músculos infrahióideos durante a contagem

IHF - músculos infrahióideos durante a frase

IHD - músculos infrahióideos durante a deglutição

ECMR - músculos esternocleidomastóideos no repouso

ECMA - músculos esternocleidomastóideos durante a emissão da vogal lal

ECMC - músculos esternocleidomastóideos durante a contagem

ECMF - músculos esternocleidomastóideos durante a frase

ECMD - músculos esternocleidomastóideos durante a deglutição

Os dados da eletromiografia foram armazenados no disco rígido do computador e posteriormente impressos em velocidade de $10 \mathrm{~ms}$ por divisão e 100 microvolts por divisão para análise. De cada traçado foram medidas as amplitudes das ondas eletrofisiológicas e considerada a maior medida como parâmetro de comparação entre os grupos. 


\subsection{Análise Estatística}

Para comparação entre os grupos disfônico e não disfônico, em relação à queixa, avaliação anteroposterior e a avaliação de perfil foi utilizado o teste qui-quadrado.

$\mathrm{Na}$ avaliação posterior, foi utilizado o Teste Exato de Fisher, pela baixa ocorrência da freqüência esperada (Zar 1996).

Para a análise dos dados da eletromiografia, foram utilizados a média, o desvio padrão e o teste "t" de Student para a comparação entre os dois grupos (Zar 1996).

Em todos os testes, fixou-se em 0,05 ou $5 \%$ o nível para rejeição da hipótese de nulidade, assinalando-se com um asterisco os valores significantes. 


\section{RESULTADOS}

Os resultados são apresentados sob forma de tabelas e gráficos e, abaixo de cada tabela, a análise estatística correspondente.

A avaliação dos dados estatísticos do presente trabalho indica que:

4.1 Com relação à queixa, não houve diferença estatisticamente significante, porém, observamos na tabela 1 e figura 11, que os portadores de disfonia apresentaram mais cervicalgia do que os não disfônicos e se igualaram quando não tiveram queixa de dor, no grupo como um todo. Não foi considerada relevante a queixa de dorsalgia e lombalgia, uma vez que a tensão muscular e a alteração postural incidiu mais na região cervical, onde se encontra situada a laringe. 
Tabela 1 - Distribuição numérica e percentual dos indivíduos quanto às algias cervical, dorsal e lombar para disfônicos e grupo controle

\begin{tabular}{lccccc}
\hline & & QUEIXA & & \\
& Cervical & Dorsal & Lombar & NÃO & TOTAL \\
\hline DISFÔNICO & 10 & 1 & 5 & 7 & 23 \\
CONTROLE & $(43,5 \%)$ & $(4,3 \%)$ & $(21,7 \%)$ & $(30,4)$ & \\
& 5 & 5 & 3 & 7 & 20 \\
TOTAL & $(25,0 \%)$ & $(25,0)$ & $(15,0 \%)$ & $(35,0 \%)$ & \\
& 15 & 6 & 8 & 14 & 43 \\
\hline
\end{tabular}

qui-quadrado $=4,65 ; p=0,200$ n.s. 


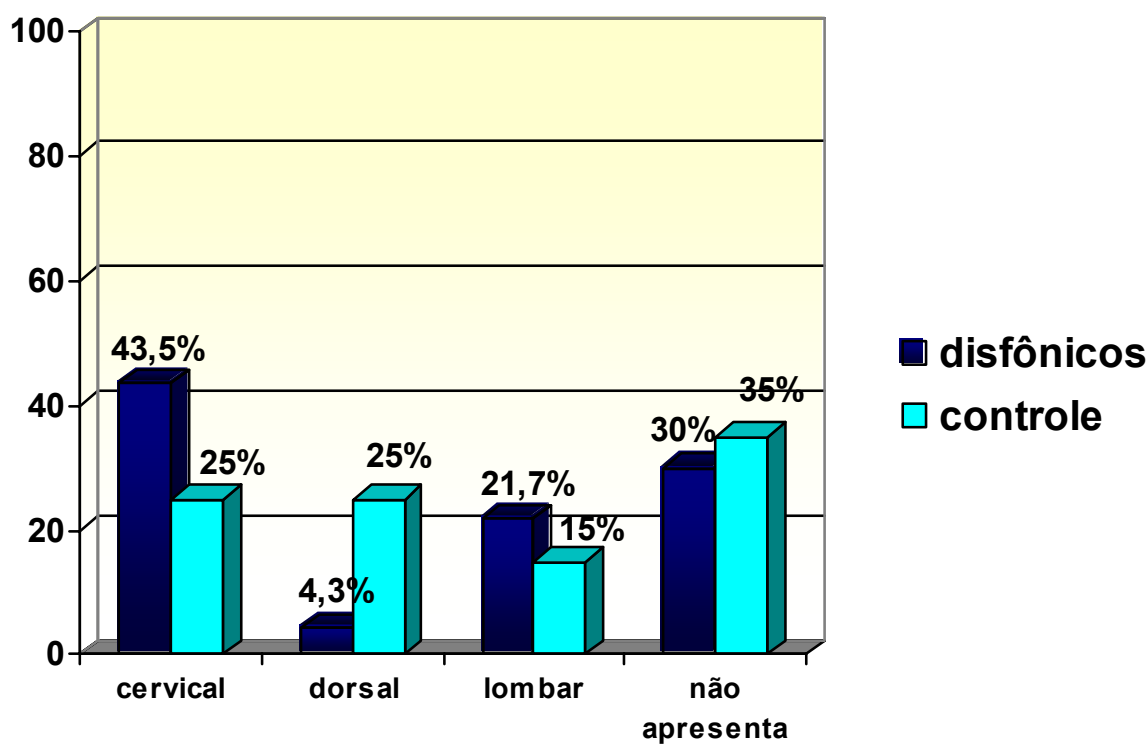

Figura 11 - Representação gráfica da presença de algias nas regiões predominantes 
4.2 No exame físico de frente (tabela 2, figura 12), foi observada existência de uma alteração em relação à assimetria dos ombros em indivíduos disfônicos quando comparados aos não disfônicos, e que foi estatisticamente significante. Quanto à face, não foram relevantes as alterações apresentadas. Referindo-se à normalidade, foi observada uma proporção relevante de normalidade em indivíduos sem disfonia, sendo aproximadamente três vezes maior nesses casos. Indivíduos disfônicos apresentaram assimetria de ombros, significantemente maior que em indivíduos do grupo controle. 
Tabela 2- Distribuição numérica e percentual da avaliação física na posição anteroposterior

\begin{tabular}{lcccc}
\hline & \multicolumn{4}{c}{$\begin{array}{c}\text { EXAME FÍSICO } \\
\text { FRENTE }\end{array}$} \\
& Com alteração & Sem alteração & \\
& Ombro & Face & Ombro ou Face & TOTAL \\
\hline DISFÔNICO & 14 & 5 & 4 & 23 \\
CONTROLE & $(60,9 \%)$ & $(21,7 \%)$ & $(17,4 \%)$ & \\
& 2 & 5 & 13 & 20 \\
TOTAL & $(10,0 \%)$ & $(25,0)$ & $(65,0 \%)$ & 43 \\
& 16 & 10 & 17 & \\
\hline
\end{tabular}

qui-quadrado=13,62; $p=0,001^{*}$

Teste de proporções (Zar, 1996): mostrou diferença significante entre os indivíduos com alteração no ombro $(\mathrm{O})$ e os normais (sem tal alteração), mas não entre aqueles com alteração na face e os normais (sem tal alteração). 


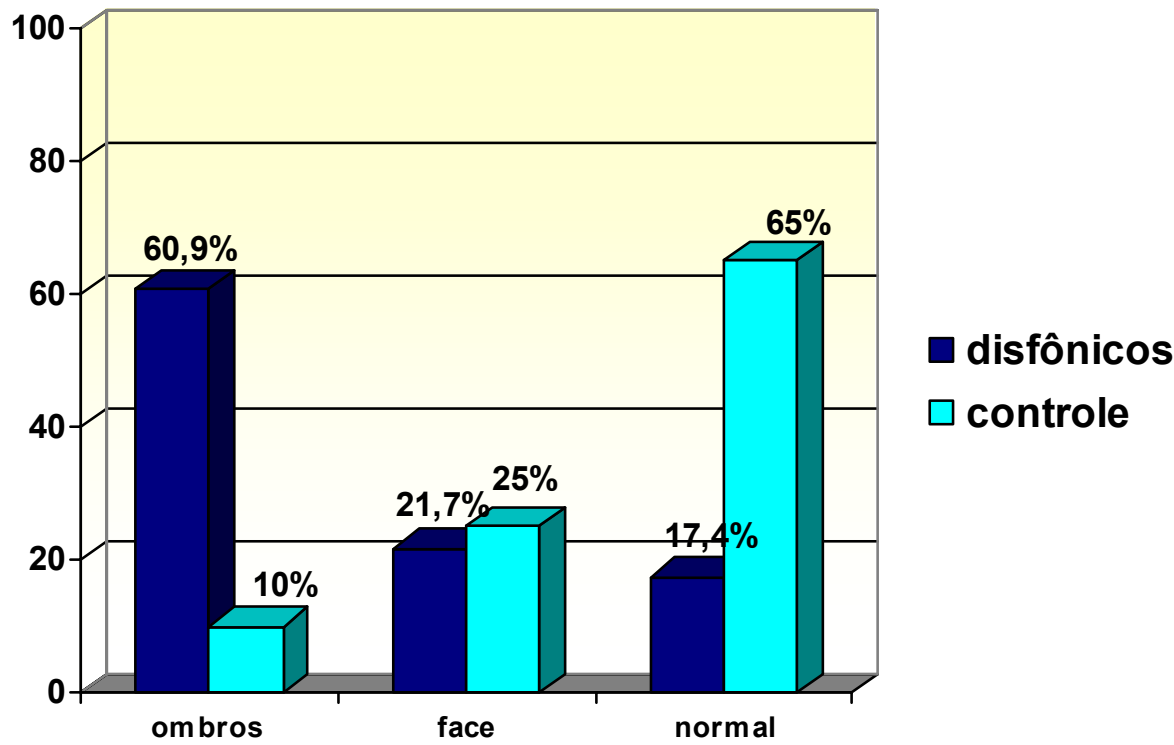

Figura 12- Representação gráfica de regiões assimétricas 
4.3 Nas tabela 3 e figura 13, na avaliação postural de perfil, foi observada a retificação com anteriorização em quase todos os pacientes disfônicos, o que não ocorreu nos indivíduos do grupo controle, sendo esta diferença estatisticamente significante. 
Tabela 3 - Distribuição numérica e percentual da avaliação postural posição perfil

\begin{tabular}{cccc}
\hline & \multicolumn{2}{c}{ EXAME FÍSICO } \\
& PERFIL & & \\
& R/A & S/ ALTER. & TOTAL \\
\hline DISFÔNICO & 20 & 3 & 23 \\
CONTROLE & $(87,0 \%)$ & $(13,0 \%)$ & \\
& 0 & 20 & 20 \\
TOTAL & $(0,0 \%)$ & $(100,0)$ & \\
& 20 & 23 & 43 \\
\hline
\end{tabular}

qui-quadrado $=29,11 ; p<0,001^{*}$

$\mathrm{R} / \mathrm{A}=$ retificação e anteriorização 


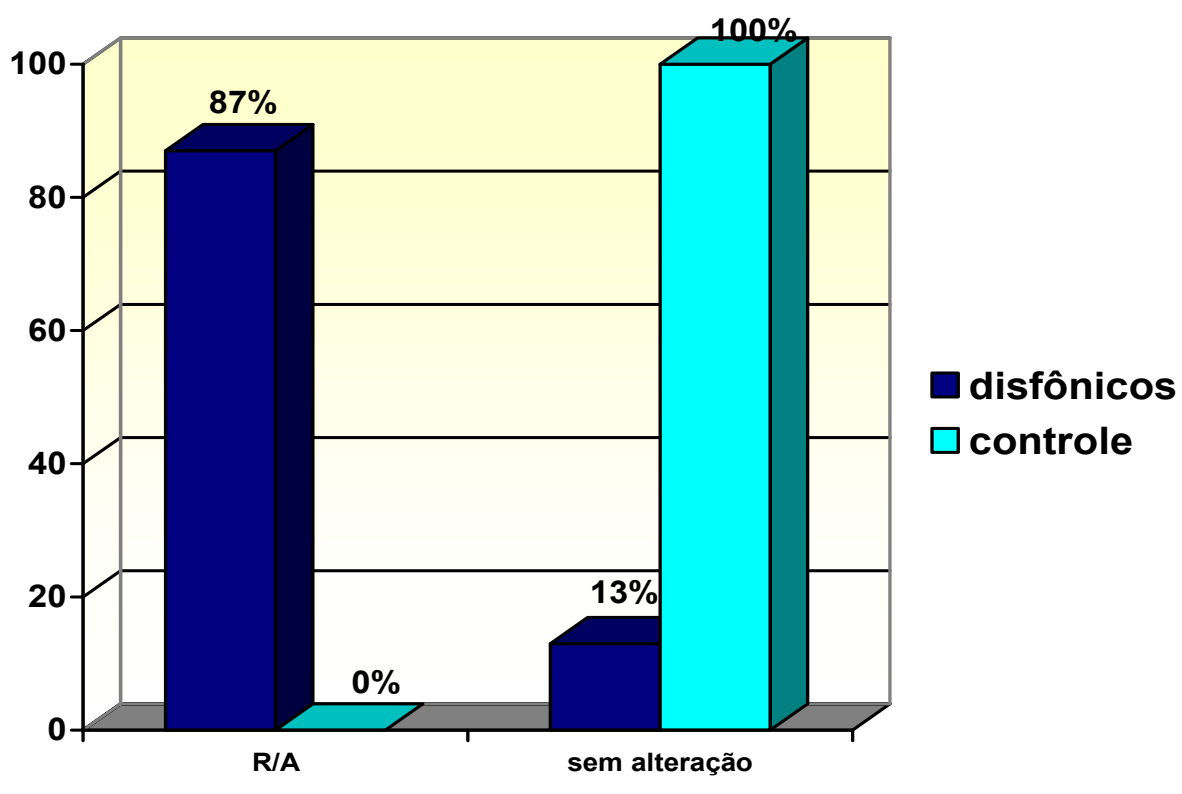

Figura 13 - Representação gráfica da avaliação postural - posição perfil 
4.4 $\mathrm{Na}$ avaliação posterior, foi observado um elevado índice de normalidade tanto nos indivíduos disfônicos quanto no grupo controle (tabela 4, figura 14). Porém, apenas no grupo disfônico foi encontrada alteração no posicionamento da escápula, que também, foi considerado estatisticamente significante. 
Tabela 4- Distribuição numérica e percentual da avaliação postural posição posterior, segundo a presença de alterações para disfônicos e grupo controle

\begin{tabular}{lccc}
\hline & \multicolumn{3}{c}{ EXAME FÍSICO } \\
& POSTERIOR & \\
& S/ ALTER & ALADA & TOTAL \\
\hline DISFÔNICO & 18 & 5 & 23 \\
& $(78,3 \%)$ & $(21,7 \%)$ & \\
CONTROLE & 20 & 0 & 20 \\
& $(100,0 \%)$ & $(0,0)$ & \\
TOTAL & 38 & 5 & 43 \\
& $(88,4 \%)$ & $(11,6 \%)$ & \\
\hline
\end{tabular}

Teste exato de Fisher $p=0,035^{*}$ 


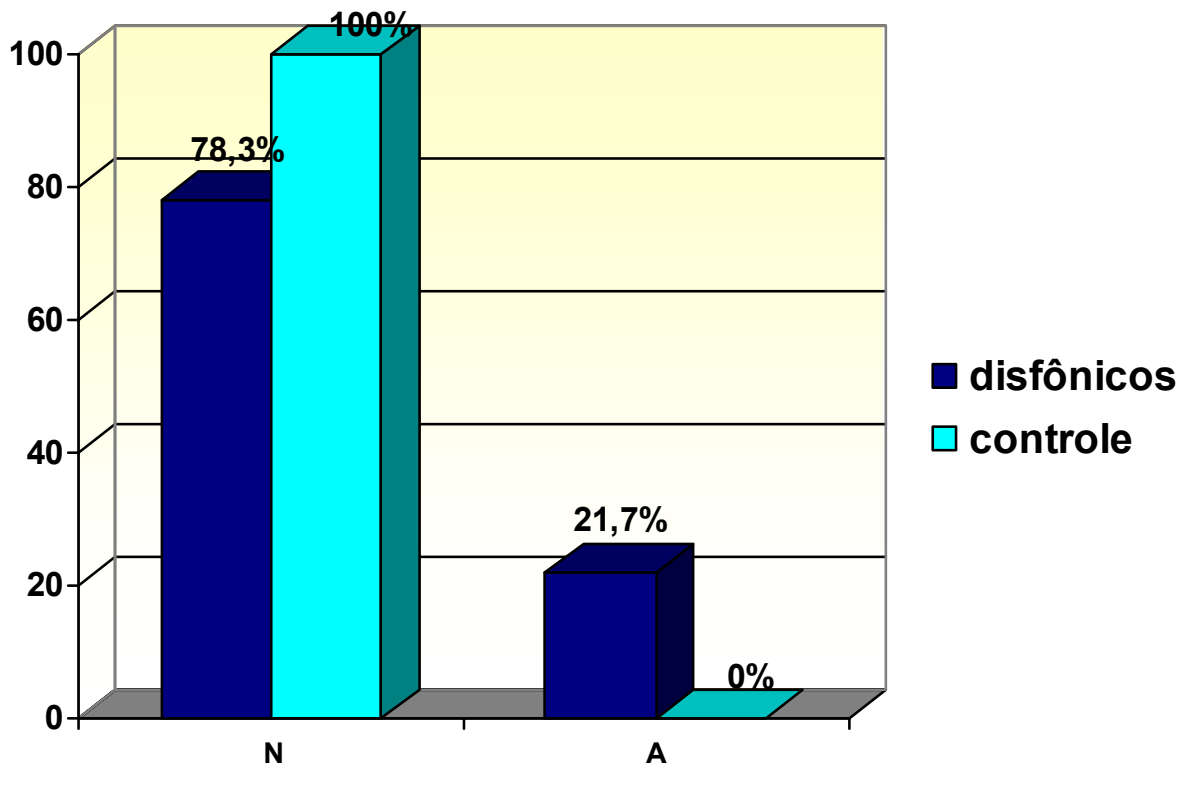

Figura 14 - Representação gráfica da avaliação postural - posição posterior 
4.5 Com relação aos resultados da eletromiografia, apresentados na tabela 5, foi observada uma diferença estatisticamente significante; nas medidas SHA suprahióideo durante a emissão do la/ prolongado, SHC - suprahióideo durante a contagem, SHD - suprahióideo durante a deglutição, IHA infrahióideo durante a emissão do la/ prolongado, demonstrando, pelos traçados eletromiográficos, haver maior atividade desses músculos durante as referidas situações. 
TABELA 5 - Distribuição dos maiores valores de amplitude da onda da eletromiografia segundo músculos e grupo de indivíduos (Média, Desvio Padrão e Teste "t")

\begin{tabular}{|c|c|c|c|c|c|c|c|}
\hline \multirow{2}{*}{ MEDIDA } & \multicolumn{2}{|c|}{ DISFÔNICO } & \multicolumn{2}{|c|}{ NÃO DISFÔNICO } & \multirow[t]{2}{*}{ Valor de "t" } & \multirow{2}{*}{\multicolumn{2}{|c|}{ Valor de $p$}} \\
\hline & $x$ & $\mathrm{dp}$ & $\bar{X}$ & $\mathrm{dp}$ & & & \\
\hline SHR & 0,3 & 0,17 & 0,35 & 0,17 & $-0,454$ & 0,652 & NS \\
\hline SHA & $1,03^{*}$ & $0,66^{*}$ & $0,59^{*}$ & $0,22^{*}$ & $2,871^{*}$ & $0,006^{*}$ & \\
\hline SHC & $1,54^{*}$ & $0,95^{\star}$ & $1,03^{*}$ & $0,50^{*}$ & $2,147^{*}$ & $0,037^{*}$ & \\
\hline SHF & 1,67 & 0,97 & 1,19 & 0,50 & 1,975 & 0,550 & NS \\
\hline SHD & $2,11^{*}$ & $1,48^{*}$ & $1,17^{*}$ & $0,70^{*}$ & $2,597^{*}$ & $0,012^{*}$ & \\
\hline IHR & 0,33 & 0,12 & 0,40 & 0,20 & $-1,383$ & 0,173 & NS \\
\hline IHA & $1,05^{*}$ & $0,50^{*}$ & $0,76^{*}$ & $0,28^{*}$ & $2,218^{*}$ & $0,032^{*}$ & \\
\hline $\mathrm{IHC}$ & 1,19 & 0,65 & 1,15 & 0,70 & 0,157 & 0,875 & NS \\
\hline IHF & 1,06 & 0,40 & 1,07 & 0,50 & $-0,128$ & 0,898 & NS \\
\hline IHD & 1,25 & 0,82 & 0,92 & 0,35 & 1,622 & 0,112 & NS \\
\hline ECMR & 0,33 & 0,20 & 0,38 & 0,15 & $-0,883$ & 0,382 & NS \\
\hline ECMA & 0,61 & 0,24 & 0,53 & 0,21 & 1,099 & 0,278 & NS \\
\hline ECMC & 0,64 & 0,25 & 0,60 & 0,31 & 0,346 & 0,730 & NS \\
\hline ECMF & 0,73 & 0,44 & 0,63 & 0,21 & 0,943 & 0,350 & NS \\
\hline ECMD & 0,63 & 0,27 & 0,62 & 0,34 & 0,103 & 0,918 & NS \\
\hline
\end{tabular}

NS=diferença estatisticamente não significante

*= diferença estatisticamente significante $(p<0,05)$ 


\section{DISCUSSÃO}

A produção vocal envolve o indivíduo em uma ação através da qual ele se expressa e se inter-relaciona. Produzir uma voz adequada requer que este indivíduo, entre outras atitudes, se posicione adequadamente, sendo comum observarmos que indivíduos disfônicos têm queixas recorrentes com a relação a cansaço físico e se mostram, por vezes, extenuados após um período de comunicação.

A atitude postural em relação à cabeça e região cervical, interfere na produção vocal, sendo o enfoque desta relação uma constante preocupação para alguns autores, que sugerem serem necessários maiores estudos que possam auxiliar na correção de problemas que venham a causar desconfortos (Bricot 1999 e Cailliet 1997). Desta forma estabelece-se a importância de uma equipe multidisciplinar para uma completa avaliação, diagnóstico e tratamento das alterações posturais que se correlacionam com a voz.

Alguns autores concordam que a manutenção da postura ereta envolve lutar contra a força da gravidade (aplicada constantemente, só em uma direção e atuando sobre as diferentes partes do nosso corpo), em manter-se situado no espaço-tempo estruturado e equilibrado durante o movimento (Bricot 1999 e Rasch e Burke 1977).

O exame postural é realizado através de avaliação clínica, com o indivíduo na posição em pé, visto de frente, de costas e de perfil, sendo examinado em todos os pontos de marcação, seguido por uma base padronizada de avaliação (Bricot 1999 e Magee 2002). Muitas outras técnicas de avaliação podem ser usadas, tais como, posturograma, espelho postural, plataforma de postura, fio de prumo, baropodometria e traçado fotográfico 
(Aragão 1991, Fornasari 1994). Essa última técnica, utilizada no presente estudo, fornece com precisão a localização dos pontos anatômicos nos diferentes planos, podendo estabelecer relações entre as linhas verticais e horizontais (Fernandes et al 1998).

Em um contexto clínico, no entanto, o quanto a hipertonicidade e o desequilíbrio muscular possibilitam a hiperfunção vocal e conseqüente disfonia associada ainda não é discernível prontamente pelos procedimentos conhecidos de avaliação individual. Investigações eletromiográficas podem contribuir como ferramentas diagnósticas para mostrar estas atividades excessivas, desequilibradas ou assimétricas nos músculos intrínsecos e extrínsecos da laringe de indivíduos com distúrbios vocais (Redenbaugh e Reich 1989).

Com o intuito de detectar a atividade elétrica de vários músculos orofaciais e cervicais anteriores, Stemple et al, em 1980, propuseram a colocação de um par de eletrodos de superfície na lâmina tireóidea com o eletrodo terra diretamente sobre 0 mento. Neste estudo, traçados eletromiográficos foram obtidos quando os indivíduos eram mantidos em silêncio e enquanto liam palavras monossilábicas em uma velocidade de um por segundo. Da mesma forma, o presente estudo utilizou a avaliação de alguns músculos anteriores do pescoço em repouso e durante a fala, solicitando o /a/ prolongado, a contagem em voz alta e uma amostra de fala, como sugerido por Redenbaugh e Reich (1989). Outros trabalhos também utilizaram a eletromiografia em casos de alterações vocais (Boltezar et al 1998, Buder e Wolf 2003, Kimaid et al 2004, Pettersen e Westgaard 2005, Redenbaugh e Reich 1989 e Sulica e Blitzer 2004). 
Da anamnese aplicada aos indivíduos dos grupos disfônico e controle, foi observado, que houve uma ocorrência maior de algias cervicais em indivíduos disfônicos $(43,5 \%)$ do que em indivíduos do grupo controle (25\%) (figura 11), porém sem significância estatística.

Apesar de não fazer referência à presença de algias, na disfonia por tensão muscular, a tensão excessiva de músculos intrínsecos e extrínsecos da laringe também foi relatada por Boltezar et al (1998). Tensão da musculatura exterior da laringe e da musculatura da nuca, bem como do aparelho respiratório, é observada com freqüência nas disfonias hiperfuncionais (Hülse 1991). Böhme (1983) não descarta a influência das diferentes tensões localizadas como fator predisponível para uma disfonia crônica.

A partir desse resultado, é importante que se amplie a amostra e se estabeleçam novos estudos para elucidar esta possível correlação a fim de propor técnicas de tratamento aos quadros álgicos que podem vir acompanhando a disfonia.

Com relação à avaliação postural, na Avaliação Anteroposterior (tabela 2, figura 12) foi observada uma diferença estatisticamente significante em relação à assimetria dos ombros de indivíduos Disfônicos quando comparados aos do Grupo Controle $(60,9 \%$ X 10\%),

Já na Avaliação de Perfil (tabela 3, figura 13), foi observada a retificação com anteriorização em $87 \%$ dos indivíduos disfônicos. Este resultado chamou a atenção por ser um valor elevado, comparado a nulidade do grupo controle.

Na Avaliação Posterior (tabela 4, figura 14), foi encontrada alteração no posicionamento da escápula no grupo disfônico de aproximadamente $25 \%$, valor que apresentou diferença estatisticamente significante quando 
comparado ao do grupo não disfônico, que, em sua totalidade, não apresentou tal alteração.

Assim o indivíduo disfônico apresenta assimetria de ombros, anteriorização e retificação cervical acompanhados de escápula alada.

Segundo Fernandes et al (1998), qualquer desvio na forma da coluna vertebral, como na retificação ou na acentuação de suas curvaturas, pode gerar solicitações funcionais prejudiciais. Isso leva ao desequilíbrio da cabeça na coluna vertebral, necessitando de funções musculares compensatórias como os descritos por Forsberg et al (1985).

Os achados do presente estudo também reforçam os resultados de Mannheimer e Rosenthal apud Ribeiro et al(1997),que consideraram a "hiperatividade e o encurtamento do esternocleidomastóideo um dos principais efeitos da posição cefálica anteriorizada”,e, finalmente os de Aragão (1998), que também considerou que a flexão do pescoço para frente compromete toda a musculatura do pescoço e cintura escapular, ficando a coluna cervical retificada.

Trabalhando com indivíduos disfonicos, Kooijiman et al (2005) também encontraram a posição anteriorizada da cabeça em mais de $75 \%$ dos casos, sendo o mesmo valor encontrado para hipertonicidade do esternocleidomastoideo. A postura correta é fundamental para uma boa performance vocal (Schenider et al 1997), uma vez que a postura física tem um papel focal na respiração e na produção do volume inicial necessário para a fala.

Segundo Gould (1971), "para apreciar totalmente a importância do controle proprioceptivo da produção da voz humana, deve ser reconhecido que 
o mecanismo postural é a base de todos os outros aspectos da atividade vocal... e parece ser extremamente significante que os fusos musculares foram identificados nos músculos abdominais e intercostais, no diafragma e, mais recentemente, na musculatura laríngea extrínseca, portanto, sugerindo uma inter-relação do controle proprioceptivo". Esse autor relatou a observação de vários laringologistas sobre o espasmo muscular do pescoço que é freqüentemente acompanhado pelo espasmo laríngeo.

Os resultados da Avaliação de Perfil,corroboram com os achados de Grini (1998), que, também, observou a face projetada à frente e tensão dos músculos do pescoço, causando alterações das pregas vocais, que levaram à disfonia. Da mesma forma, Caillet (1997) concluiu que a postura anteriorizada da cabeça provoca um aumento relativo no peso da cabeça, podendo causar uma sobrecarga articular.

Já com relação aos achados observados na Avaliação Posterior, estão em consonância com Selby e Herdman (1999), para quem os ombros são considerados o centro de tensão do corpo, e podem causar má postura, fazendo uma elevação e rotação interna, tornando-os curvados, dificultando a respiração e deixando a cadeia muscular posterior com força diminuída, o que pode resultar em escápula alada e aumento da cifose dorsal. Hulse (1991) observou que a tensão dos músculos do pescoço, bem como da região da laringe causa uma disfonia funcional, sendo essa tensão produzida por um distúrbio funcional da espinha cervical superior, cuja manipulação de vértebras pode eliminar a rigidez da espinha e normalizar a voz em alguns minutos.

Para verificar a atividade muscular de forma objetiva, foi realizada, a seguir, a análise dos resultados fornecidos pela eletromiografia (tabela 5), 
observando diferenças estatisticamente significantes, entre as medidas dos músculos suprahióideos, durante a emissão do /a/ prolongado, na contagem e deglutição, como também, entre as dos músculos infrahióideos, especialmente durante a emissão do /a/ prolongado. Nesses traçados eletromiográficos, houve uma maior atividade desses músculos durante as referidas situações no grupo dos disfonicos quando comparados aos indivíduos do grupo controle.

Estes achados corroboram os obtidos da observação de postura corporal uma vez que, em decorrência das alterações posturais mais observadas, pudemos aferir medidas eletromiográficas que confirmam uma maior atividade muscular principalmente daqueles músculos diretamente envolvidos com a sustentação da laringe em situação de tensão.

Nos demais músculos, não foram registradas diferenças estatisticamente significantes, principalmente pelo posicionamento onde não tem nem origem e nem inserção próximo à laringe (Calais-Germain 1992).

Resultados que concordam com os enunciados por Forsberg et al (1985), quando o autor se refere à relação entre as diferenças de postura da cabeça e seu relacionamento com o equilíbrio e funções fisiológicas tais como a fala e deglutição. Além disso, também, reforçam a hipótese do presente estudo ao demonstrar a presença de tensão muscular ou de maior atividade muscular durante a emissão do som.

Contrariando as expectativas, nos casos que apresentavam assimetria de ombros, não foram registradas diferenças nos traçados eletromiográficos do músculo esternocleidomastóideo já que Forsberg et al (1985) encontraram alterações na atividade muscular em extensão da cabeça, não observadas no presente estudo. 
Convém lembrar, ainda, que não só o músculo esternocleidomastóideo atua sobre a articulação do ombro e sinaliza para a possibilidade de tensão, mas há a participação dos músculos trapézio, elevador da escápula. Os músculos supra e infrahióideos apresentaram alteração eletromiográfica quando houve mudança na postura da cabeça, o que também foi observado na alteração postural do indivíduo disfônico do presente estudo. Esta alteração na eletromiografia pode ser diagnosticada pela tensão muscular da referida área, o que concorda com Stemple et al (1980), quando citaram a tensão geral da musculatura da área da laringe durante a fala em indivíduos disfônicos.

Porém, existe discordância durante os traçados eletromiográficos quando comparados com o repouso ou silêncio. Isso pode ocorrer porque esses indivíduos não evidenciam atividade eletromiográfica excessiva para todas as situações de fala e não-fala, como descreve Redenbaugh e Reich (1989). Durante a emissão da vogal e outras emissões de fala, o excessivo esforço muscular que caracteriza os indivíduos com hiperfunção vocal foi demonstrado pelas medidas mais elevadas da amplitude do registro eletromiográfico, tanto no presente estudo quanto no estudo de Redenbaugh e Reich (1989).

Nesta linha de abordagem, Roy et al (1996) indicam a técnica manual para a red ução de tensão músculo-esquelética aplicada para a região da laringe, com resultados satisfatórios, sendo uma inovação clínica com uma melhora substancial da voz, segundo os autores. Já Schneider et al (1997) enfatizam a importância do alinhamento postural para os casos com disfonia, sugerindo que seja realizado um treinamento dos músculos a serem fortalecidos, usando os princípios de sobrecarga, a resistência progressiva e a 
especificidade. Segundo os autores, a aplicação desses princípios é fundamental para os profissionais que atuam com a voz.

No estudo de Forsberg et al (1985), durante a flexão de $20^{\circ}$ da cabeça em relação à coluna, houve um aumento na atividade dos músculos supra e infrahióideos, podendo ser a resposta necessária para manter a posição do osso hióideo e a permeabilidade de via aérea.

Uma vez constatadas alterações posturais e alterações eletromiográficas que indicam hiperatividade muscular nos indivíduos disfônicos de forma significantemente maior do que nos indivíduos do grupo controle, é importante salientar que inúmeras técnicas de tratamento fisioterapêutico poderão ser utilizadas na reabilitação dos indivíduos disfônicos, como terapia complementar.

Esta visão de abordagem abre a perspectiva da necessidade de novas pesquisas para adequação de um melhor método para correção da postura corporal e diminuição da tensão cervical e da laringe, complementando um trabalho que vem sendo desenvolvido há muito tempo por fonoaudiólogos e otorrinolaringologistas. 


\section{CONCLUSÃO}

O presente estudo mostra a existência de correlação positiva entre indivíduos portadores de disfonia e alteração na postura, baseado nas diferenças dos achados clínicos e das medidas eletromiográficas.

Após analisar a postura corporal do paciente disfônico e comparar os resultados com o grupo controle, conclui-se que apresentam as seguintes alterações posturais:

- assimetria de ombros;

- anteriorização e retificação de região cervical;

- escápula alada;

caracterizadas por um aumento das atividades eletromiográficas nos músculos supra-hióideos em emissão prolongada, emissão controlada e durante a deglutição; e nos músculos infra-hióideos durante a emissão prolongada. 


\section{REFERÊNCIAS BIBLIOGRÁFICAS}

Aragão W. Aragon's function regulator, the stomathognathic system and postural changes in children. J Clin Pediatr Dent 1991; 15:226-31.

Basmajian JV. Muscles alive: their functions revealed by eletromiography. 4a. ed. Baltimore: Willians and Wilkins; 1978.

Boltezar IH, Janko M, Zargi M. Role of surface EMG in diagnostic and treatment of muscle tension dysphonia. Acta Otolaryngol (Stockh) 1998; 118:738-43.

Behlau M (org). Voz: O Livro do Especialista. Rio de Janeiro: Revinter; 2001.

Behlau M, Pontes P. Avaliação e tratamento das disfonias. São Paulo: Lovise; 1995.

Behrman A. Commom pratices of voice therapists in the evaluation of patients. J Voice 2005; 19:454-9.

Böhme G. Klinik der Sprach-, Spreech- und Stimmstörungen, Aufl. Stuttgart: Fischer; 1983.

Bricot B. Posturologia. Tradução por Ângela Bushatsy. São Paulo: Ícone; 1999. Tradução de: A reprogramation posturale globale.

Buder $\mathrm{EH}$, Wolf $\mathrm{T}$. Instrumental and perceptual evaluations of two related singers. J Voice 2003; 17: 228-44.

Callais-Gremane B. Anatomia para o movimento. São Paulo: Manole; 1991.

Callegar-Jacques SM. Bioestatística: Princípios e Aplicações. Porto Alegre: Artmed; 2003.

Cailliet R. Síndromes dolorosas da cabeça e da face. Rio de Janeiro: Revinter; 1997. 233p. 
Collins J. Education techniques for lifelong learning: giving a PowerPoint presentation: the art of communicating effectively. Radiographics 2004; 24 : 1185-92.

De Biase NG. Alterações estruturais mínimas da cobertura das pregas vocais. Estudo comparativo dos vasos sanguíneos à videotelelaringoscopia [tese]. São Paulo: Universidade Federal de São Paulo; 1997.

Frempong-Boadu A, Houten JK, Osborn B, Opulencia J, Kells L, Guida DD et al. Swallowing and speech dysfunction in patients undergoing anterior cervical discectomy and fusion: a prospective, objetive preoperative and posoperative assessment. J Spinal Disord Tech 2002; 15:362-8.

Fornasari CA. Repensando a clássica avaliação postural. Fisioter Mov 1994; 6:40-53.

Gould WJ. Effects of Respiratory and Postural Mechanisms upon Action of the Vocal Cords. Folia Phoniatr 1971; 23: 211-14.

Gregg JW. The singing/acting mature adult-singing instruction perspective. $J$ Voice 1997; 11:165-70.

Grini-Grandval MN, Ouaknine M, Giovanni A. Forcing the voice and variance of speed: correlation between the speed of displacement of the center of gravity and the postural muscles. Rev Laryngol Otol Rhinol 2000; 121:319-23.

Grini MN, Oaknine M, Giovanni A. Contemporary postural and segmental modification of forced voice. Rev. Laryngol Otol Rhinol 1998; 119:253-7.

Fernandes E, Mochizuki L, Duarte M, Bojadsen TWA, Amadio AC. Estudo biomecânico sobre os métodos de avaliação postural. Rev Bras de Postura e Movimento 1998; 2: 5-14. 
Forsberg CM, Hellsing E, Linder-Aronson S, Sheikholeslam A. EMG activity in neck and masticatory muscles in relation to extension and flexion of the head. Eur J Orthod 1985; 7:177-84.

Hartman DE, Sanchez A, McDonnell D, Bouri AK, Overholt EM, Sieck BM. Dysphonia and dysfagia following anterior cervical diskectomy and fusion. $J$ Med Speech-Language Pathology 2005; 13:141-7.

Hulse M. Cervical dysphonia. Folia Phoniatr (Basel) 1991; 43:181-96.

Jones FP. Voice production as function of head balance in singers. J Phychol 1972; 82:209-15.

Kendall FP, McCreary EK. Músculos - prova e funções. São Paulo: Manole; 1987.

Kimaid PA, Quagliato EM, Crespo AN, Wolf A, Viana MA, Resende LA. Laryngeal electromyography in movement disorders: preliminary data. Arq Neuropsiquiatr 2004; 62: 741-4.

Kooijiman PGC, De Jong FICRS, Oudes MJ, Huinck W, Van Acht H, Graamans K. Muscular tension and body posture in relation to voice handicap and voice quality in teachers with persistent voices complaints. Folia Phoniatr Logop $2005 ; 57: 134-47$.

Krakauer LH e Guilherme A. Relação entre respiração bucal e alterações posturais em crianças:uma analise descritiva. Rev Dental Press Ortodon Ortoped Facial 2000; 5:85-92.

Lacôte M, Chevalier AM, Miranda A, Bleton JP, Stevenin P. Avaliação clínica da função muscular. São Paulo: Manole; 1987.

Magee D. Avaliação músculo-esquelética. 3a.ed. Barueri: Manole; 2002. 
Morrison M. Pattern recognition in muscle misuse voice disorders: how I do it. $J$ Voice 1997; 11:108-14.

Ogawa M, Yoshida M, Watanabe K, Yoshi T, Sugiyama Y, Sasaki R et al. Association between laryngeal findings and vocal qualities in muscle tension dysphonia with supraglottic contraction. J Otolaryngol Japan 2005; 108:73441.

Pettersen V, Westgaard RH. The activity patterns of neck muscles in professional classical singing. J Voice 2005; 19(2):238-51.

Pinho SMR, Pontes PAL, Gadelha MEC, Biasi N. Vestibular vocal fold behaviour during phonation in unilateral vocal fold paralysis. $J$ of Voice 1999; 13:36-42.

Rasch PJ, Burke RK. Cinesiologia e anatomia aplicada. 5a.ed. Rio de Janeiro: Guanabara Koogan; 1977.

Redenbauch MA, Reich AR. Surface and related measures in normal and vocally hyperfunctional speakers. J Speech Hear Disord 1989; 54:68-73.

Ribeiro EC, Marchiori SC, Silva AMT. Eletromiografia dos músculos esternocleidomastoideo e trapézio em crianças respiradoras bucais e nasais durante correção postural. Arq Otorrinolaringol 2003; 7:13-19.

Roy N, Ford CN, Bless DM. Muscle tension dysphonia and spasmodic dysphonia: the role of manual larungeal tension reduction in diagnosis and management. Ann Othol Rhinol Laryngol 1996; 105:851-6.

Salvinelli F, Marte C, Firrisi L, D'ascanio L, Casale M, Lamanna F et al. Dysphonia and cervical hyperostosis: a case report. Rev Laryngol Otol Rhinol (Bord) 2003; 124:191-3. 
Selby A, Herdman A. Pilates - como criar o corpo que você deseja. São Paulo: Manole; 1999.

Shneider CM, Dennehy CA, Saxon KG. Exercise physiology principles applied to vocal performance: the improvement of postural alignment. $J$ Voice 1997; 11:332-7.

Souchard PE. Reeducação postural global (método de corpo fechado). São Paulo: Manole; 1987. As auto-posturas respiratórias. São Paulo: Manole; 1997. 82p.

Stemple JC, Weiler E, Whitehead W, Komray R. Eletromyographic biofeedback training with patients exhibiting a hyperfuncional voice disorder. Laryngoscope 1980; 90:471-6.

Sulica L, Blitzer A. Botulinum toxin treatment of spasmodic dysphonia. Operative Techniques in Otolaryngology - Head and Neck Surgery 2004; 15 : 76-80.

Winslow CP, Winslow TJ, Wax MK. Dysphonia and dysphagia following the anterior approach to the cervical spine. Arch Otolaryngol Head Neck Surgery $2001 ; 127: 51-5$

Xue A, Mueller P.B. Acoustic and perceptual characteristics of the voices of sedentary and physically active elderly speakers. Log Phon Vocol 1997; 22:51-60. 


\section{Anexo 1- APROVAÇÃO DO COMITÊ DE ÉTICA EM PESQUISA}

Ofício $n^{\circ}$ 056/2004-UEP-CEP

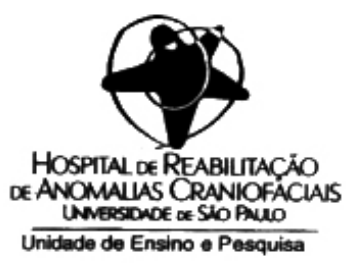

Bauru, 03 de maio de 2004.

Prezado(a) Senhor(a)

O projeto de pesquisa encaminhado a este Comitê de Ética em Pesquisa em Seres Humanos, denominado "Estudo da postura corporal em portadores de disfonia", de autoria de V.S", foi enviado ao relator para avaliação.

Na reunião de 28 de abril de 2004 o parecer do relator, aprovando o projeto, foi aceito pelo Comitê, considerando que não existem infrações éticas pendentes para início da pesquisa.

A pesquisadora fica responsável pela entrega na Unidade de Ensino e Pesquisa dos relatórios semestrais.

Informamos que após o recebimento do trabalho concluído, este Comitê enviará o parecer final para publicação.

Atenciosamente



PROF. DR. ROBERTO LOUREIRO MARINGONI

Coordenador do Comitê de Ética em Pesquisa do HRAC-USP

$\operatorname{lmo}(\mathrm{a}) \operatorname{Sr}(\mathrm{a})$

Eloísa Ap. Nelli

Fisioterapia - HRAC/USP 


\section{Anexo 2 - CARTA DE INFORMAÇÃO AO SUJEITO DA PESQUISA}

A presente pesquisa tem como objetivo investigar uma possível correlação entre postura e problemas de voz visando melhorar o atendimento para proporcionar o bem-estar dos pacientes.

A avaliação será realizada por uma fisioterapeuta e uma fonoaudióloga que observarão a postura em pé e sentado. Todas as posições serão fotografadas, porém, não sendo identificado. Além disso, faremos um exame chamado eletromiografia para ver a tensão dos músculos do pescoço, com o uso de estimulação elétrica superficial. Este procedimento não traz desconfortos, nem riscos.

A participação do sujeito terá como benefício o diagnóstico fisioterápico e fonoaudiológico, com orientações e encaminhamento para tratamento.

Estaremos à disposição para responder perguntas e prestar esclarecimentos a qualquer dúvida em relação aos procedimentos e benefícios de nosso trabalho. Esclarecemos que fica de livre arbítrio a participação do indivíduo, bem como desistência deste estudo.

"Caso o sujeito da pesquisa queira apresentar reclamações em relação à sua participação na pesquisa, poderá entrar em contato com o Comitê de Ética em Pesquisa em Seres Humanos do HRAC-USP, pelo endereço Rua Sílvio Marchione 3-20, na Unidade de Ensino e Pesquisa ou pelo telefone 32358421." 


\section{Anexo 3 -TERMO DE CONSENTIMENTO LIVRE E ESCLARECIDO}

$\mathrm{Eu}$, portador do RG $\mathrm{n}^{\circ}$ residente à Rua (Av.)

$n^{\circ}$ , na cidade de Estado ,concordo em participar na pesquisa de Título "Estudo da postura corporal em portadores de disfonia", realizada por Eloisa Aparecida Nelli (CREFITO 1587F), sob orientação do Prof. Dr.Arnaldo Guilherme (CRM 28382).

A referida pesquisa tem como objetivo investigar uma possível correlação entre postura e problemas de voz visando melhorar o atendimento para proporcionar o bemestar dos pacientes.

Fui orientado que a avaliação será realizada por uma fisioterapeuta e uma fonoaudióloga que observarão a postura em pé e sentado. Todas as posições serão fotografadas, porém, não sendo identificado. Além disso, faremos um exame chamado eletromiografia para ver a tensão dos músculos do pescoço, com o uso de estimulação elétrica superficial.

Estou ciente também de que minha participação é voluntária e dela posso desistir a qualquer momento, sem explicar os motivos.

Bauru, 1

Paciente

Nome do Pesquisador Responsável: Eloísa Aparecida Nelli

Endereço Institucional: Rua Sílvio Marchione 3-20

Cidade: Bauru Estado: $\mathbf{S P}$ CEP: $17043-900$

Telefone: (14) 3235-8088 


\section{Anexo 4 - FICHA DE EXCLUSÃO}

Nome

Idade

Sexo

1 - É portador de alguma doença reumática?

Sim ( ) Não ( )

2 - Tem má formação óssea?

Sim ( ) Não ( )

3 - Apresenta desvio postural?

Sim ( ) Não ( )

4 - Qual?

Escoliose ( ) Dorso curso ( ) Hiperlordose ( )

5 - É portador de paralisia cerebral?

Sim ( ) Não ( )

6 - É portador de alguma síndrome genética?

Sim ( ) Não ( )

7 - Apresenta fraturas?

Sim ( ) Não ( )

8 - Localizadas em:

Vértebras ( ) Membros superiores ( ) Cintura escapular ( ) 


\section{Anexo 5- PROTOCOLO DE AVALIAÇÃO POSTURAL}

NOME:

DATA DE NASCIMENTO:

SEXO :

RG:

ANAMINESIA : DOR

( ) CERVICAL

( ) DORSAL

( ) LOMBAR

QDO PERDEU A VOZ :

DESCRIÇÃO DA POSTURA:

POSIÇÃO :

FRENTE : ASSIMETRIA FACIAL

( ) SIM ( ) NÂO

LINHA DOS LOBULOS AURICULARES: ( ) SIMETRICO ( ) ASS

ALTURA DOS OMBROS:

( )IGUAIS ( ) ALTERADO

ALTURA DAS CLAVICULAS:

( )IGUAIS ( ) ALTERADO

TRIANGULO DE TALLES:

( )IGUAIS ( )ALTERADO

ALTURA DA CRISTA ILIACA:

( )IGUAIS ( ) ALTERADO

ALTURA DE JOELHOS:

( )IGUAIS ( ) ALTERADOS

ALTURA DOS MALEOLOS:

( )IGUAIS ( ) ALTERADO 
PERFIL:

CERVICAL ( ) CIFOSE ( ) LORDOSE ( ) RETIFICADA ( ) NORMAL DORSAL ( ) CIFOSE ( ) LORDOSE ( ) RETIFICADA ( ) NORMAL LOMBAR ( ) CIFOSE ( ) LORDOSE ( ) RETIFICADA ( ) NORMAL COSTA : ESCAPULA ( ) ALADA ( ) NORMAL ALTURA ( ) NORMAL ( ) ALTERADA LINHA GLUTEA ( ) NORMAL ( ) ALTERADA POSIÇÃO DE CALCANEO( ) NORMAL （） ALTERADA FOTOS 


\section{Anexo 6- BANCO DE DADOS DO GRUPO NÃO DISFÔNICO}

\begin{tabular}{|c|c|c|c|c|c|c|}
\hline & Nome & Idade & Queixa & FR & $\mathbf{P}$ & C \\
\hline 1 & T.C. & $22 a 9 m$ & dorsal & Face $\neq$ & $\mathrm{N}$ & $\mathrm{N}$ \\
\hline 2 & J.M.Z. & $23 a 1 m$ & cervical & $\mathrm{N}$ & $\mathrm{N}$ & $\mathrm{N}$ \\
\hline 3 & C.F. & $25 a 1 m$ & cervical & Face $\neq$ & $\mathrm{N}$ & $\mathrm{N}$ \\
\hline 4 & M.P.P. & $24 a 1 m$ & cervical & Ombro $\neq$ & $\mathrm{N}$ & $\mathrm{N}$ \\
\hline 5 & G.S.R. & $24 a 5 m$ & dorsal & $\mathrm{N}$ & $\mathrm{N}$ & $\mathrm{N}$ \\
\hline 6 & R.M.G. & $38 a 2 m$ & não tem & $\mathrm{N}$ & $\mathrm{N}$ & $\mathrm{N}$ \\
\hline 7 & V.M.R. & $36 a$ & dorsal & Ombro $\neq$ & $\mathrm{N}$ & $\mathrm{N}$ \\
\hline 8 & C.R.L.P. & $36 a 6 m$ & não tem & Ombro $\neq$ & $\mathrm{N}$ & $\mathrm{N}$ \\
\hline 9 & J.S.S. & $18 \mathrm{a} 10 \mathrm{~m}$ & não tem & $\mathrm{N}$ & $\mathrm{N}$ & $\mathrm{N}$ \\
\hline 10 & K.C.A.C. & $35 a 7 m$ & não tem & $\mathrm{N}$ & $\mathrm{N}$ & $\mathrm{N}$ \\
\hline 11 & R.M. & $25 a 1 m$ & cervical & $\mathrm{N}$ & $\mathrm{N}$ & $\mathrm{N}$ \\
\hline 12 & R.C.C.A. & $24 a 1 m$ & dorsal & $\bar{N}$ & $\mathrm{~N}$ & $\mathrm{~N}$ \\
\hline 13 & Z.M. & $37 a 10 m$ & não tem & Ombro $\neq$ & $\mathrm{N}$ & $\mathrm{N}$ \\
\hline 14 & J.N. & $22 a 5 m$ & não tem & $\mathrm{N}$ & $\mathrm{N}$ & $\mathrm{N}$ \\
\hline 15 & M.L.V. & $38 a 8 m$ & lombar & $\bar{N}$ & $\mathrm{~N}$ & $\mathrm{~N}$ \\
\hline 16 & M.S. & $31 \mathrm{a} 11 \mathrm{~m}$ & lombar & Ombro $\neq$ & $\mathrm{N}$ & $\mathrm{N}$ \\
\hline 17 & M.N.L.V. & $24 a 6 m$ & lombar & $\mathrm{N}$ & $\mathrm{N}$ & $\mathrm{N}$ \\
\hline 18 & M.N.L.V. & $26 a$ & Não tem & $\mathrm{N}$ & $\mathrm{N}$ & $\mathrm{N}$ \\
\hline 19 & A.R.S. & 29a3m & Cervical & $\mathrm{N}$ & $\mathrm{N}$ & $\mathrm{N}$ \\
\hline 20 & L.S. & $39 a 3 m$ & Dorsal & $\mathrm{N}$ & $\mathrm{N}$ & $\mathrm{N}$ \\
\hline
\end{tabular}

\section{LEGENDA}

FR - Frente / P-Perfil / C-Costa 
Anexo 7 - BANCO DE DADOS DO GRUPO DISFÔNICO

\begin{tabular}{|c|c|c|c|c|c|c|}
\hline & Nome & Idade & Queixa & FR & $\mathbf{P}$ & C \\
\hline 1 & J.C.S.S. & $18 \mathrm{a} 10 \mathrm{~m}$ & cervical & Ombro $\neq$ & $\mathrm{R}$ & $\mathrm{N}$ \\
\hline 2 & A.N.O.S. & $34 a 10 m$ & cervical & Ombro $\neq$ & $\mathrm{R}$ & $\mathrm{N}$ \\
\hline 3 & V.C. & 23a1m & cervical & Ombro $\neq$ & $\mathrm{R}$ & $\begin{array}{c}\text { Alada E } \\
\qquad A \neq\end{array}$ \\
\hline 4 & F.F.V. & $27 a 7 m$ & lombar & Ombro $\neq$ & $\mathrm{R}$ & $\mathrm{N}$ \\
\hline 5 & I.S.A. & $28 a 3 m$ & lombar & Face $\neq$ & $\mathrm{R}$ & $\mathrm{N}$ \\
\hline 6 & T.P.G. & $18 \mathrm{a} 6 \mathrm{~m}$ & cervical & Ombro $\neq$ & $\mathrm{R}$ & $\mathrm{N}$ \\
\hline 7 & F.S.O. & $28 a 10 m$ & não tem & Face $\neq$ & $\mathrm{N}$ & $\begin{array}{c}\text { Alada D } \\
\mathrm{D} \uparrow\end{array}$ \\
\hline 8 & S.B.M. & $35 a 9 m$ & lombar & Ombro $\neq$ & $\mathrm{R}$ & $\mathrm{N}$ \\
\hline 9 & A.P.S. & $27 a 4 m$ & cervical & Face $\neq$ & $\mathrm{R}$ & Alada \\
\hline 10 & D.F.O. & $22 a 9 m$ & cervical & Lóbulos $\neq$ & $\mathrm{N}$ & $\mathrm{N}$ \\
\hline 11 & E.C.S. & $32 a 9 m$ & cervical & ombro $\neq$ & $\mathrm{R}$ & Alada \\
\hline 12 & L.A.B. & 32a11m & não tem & Ombro $\neq$ & $\mathrm{N}$ & $\mathrm{N}$ \\
\hline 13 & S.S.G. & $31 \mathrm{a} 8 \mathrm{~m}$ & lombar & Face $\neq$ & $\mathrm{R}$ & $\mathrm{N}$ \\
\hline 14 & L.A.S. & $23 a 11 m$ & lombar & Ombro $\neq$ & $\mathrm{R}$ & $\bar{N}$ \\
\hline 15 & M.F.C. & $26 a 2 m$ & dorsal & Sem alter. & $\mathrm{R}$ & $\mathrm{N}$ \\
\hline 16 & T.A.C. & $26 a 1 m$ & não tem & ombro $\neq$ & $\mathrm{R}$ & $\mathrm{N}$ \\
\hline 17 & E.O.O.G. & $25 a 4 m$ & não tem & Sem alter. & $\mathrm{R}$ & $\mathrm{N}$ \\
\hline 18 & J.M.O. & $36 \mathrm{a} 0 \mathrm{~m}$ & cervical & Ombro $\neq$ & $\mathrm{R}$ & $\mathrm{N}$ \\
\hline 19 & C.M.S. & $31 a$ & não tem & Sem alter. & $\mathrm{R}$ & $\mathrm{N}$ \\
\hline 20 & D.A.A.S. & $39 a 4 m$ & cervical & Face & $\mathrm{R}$ & $\mathrm{N}$ \\
\hline 21 & L.R.S. & $31 \mathrm{a} 2 \mathrm{~m}$ & cervical & Ombro & $\mathrm{R}$ & $A$ \\
\hline 22 & R.C.B. & $34 a 10 m$ & Não tem & Sem alteração & $\mathrm{R}$ & $\bar{N}$ \\
\hline 23 & A.P.M.S. & $21 \mathrm{a} 10 \mathrm{~m}$ & Não tem & Ombro & $\mathrm{R}$ & $\mathrm{N}$ \\
\hline
\end{tabular}

LEGENDA:

FR - Frente / P-Perfil / C- Costa 